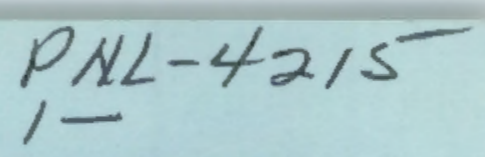

NUREG/CR-2264 PNL-4215

\title{
Characterization Methods for Ultrasonic Test Systems
}

Prepared by L. J. Busse, F. L. Becker, R. E. Bowey,

S. R. Doctor, R. P. Gribble, G. J. Posakony

Pacific Northwest Laboratory

Operated by

Battelle Memorial Institute

Prepared for

U.S. Nuclear Regulatory

Commission 


\section{NOTICE}

This report was prepared as an account of work sponsored by an agency of the United States Government. Neither the United States Government nor any agency thereof, or any of their employees, makes any warranty, expressed or implied, or assumes any legal liability or responsibility for any third party's use, or the results of such use, of any information, apparatus product or process disclosed in this report, or represents that its use by such third party would not infringe privately owned rights.

\section{Available from}

GPO Sales Prograni

Division of Technical Information and Documen: Control

U. S. Nuclear Regulatory Commission

Washington, D. C. 20555

Printed copy price: $\$ 5.00$

and

National Technical Information Service

Springfield, Virginia 22161 
NUREG/CR-2264

PNL-4215

R5

\section{Characterization Methods for Ultrasonic Test Systems}

Manuscript Completed: April 1982

Date Published: July 1982

Prepared by

L. J. Busse, F. L. Becker, R. E. Bowey,

S. R. Doctor, R. P. Gribble, G. J. Posakony

Pacific Northwest Laboratory

Richland, WA 99352

Prepared for

Division of Engineering Technology

Office of Nuclear Regulatory Research

U.S. Nuclear Regulatory Commission

Washington, D.C. 20555

NRC FIN B2289 



\begin{abstract}
Methods for the characterization of ultrasonic transducers (search units) and instruments are presented. The instrument system is considered as three separate components consisting of a transducer, a receiver-display, and a pulser. The operation of each component is assessed independently. The methods presented were chosen because they provide the greatest amount of information about component operation and were not chosen based upon such conditions as cost, ease of operation, field implementation, etc. The results of evaluating a number of commercially available ultrasonic test instruments are presented.
\end{abstract}





\section{SUMMARY}

A common goal of those working in the area of ultrasonic testing is the development of effective and reproducible test results. To meet this goal, ultrasonic instrument operation must be repeatable and predictable. This document presents a series of measurement techniques that are being used at Pacific Northwest Laboratory (PNL) to quantify the performance of ultrasonic test instruments. The purpose of these techniques is to provide the greatest amount of information about the operating characteristics of the individual components that make up an ultrasonic test instrument.

U1trasonic test instruments are considered as three subsystems: a transducer or search unit, a receiver-display, and a pulser. The performance of each subsystem is assessed independently. The measurement procedures described allow the following properties to be determined:

1. Transducer

- acoustic firequency response (spectrum)

- efficiency (insertion loss or pulse echo sensitivity)

- time domain response

- electrical impedance

- sound field patterns

2. Receiver-Display

- frequency rosponse (bandwidth)

- amplitude response (1 inearity)

- noise (referred to input)

- input sensilivity

3. Pulser

- time domain response

- frequency response

- output impedance 
Measurement procedures have been demonstrated on commercially available transducers and test instruments. A discussion of the results is presented as well as some general suggestions for improvement of instrument performance. 


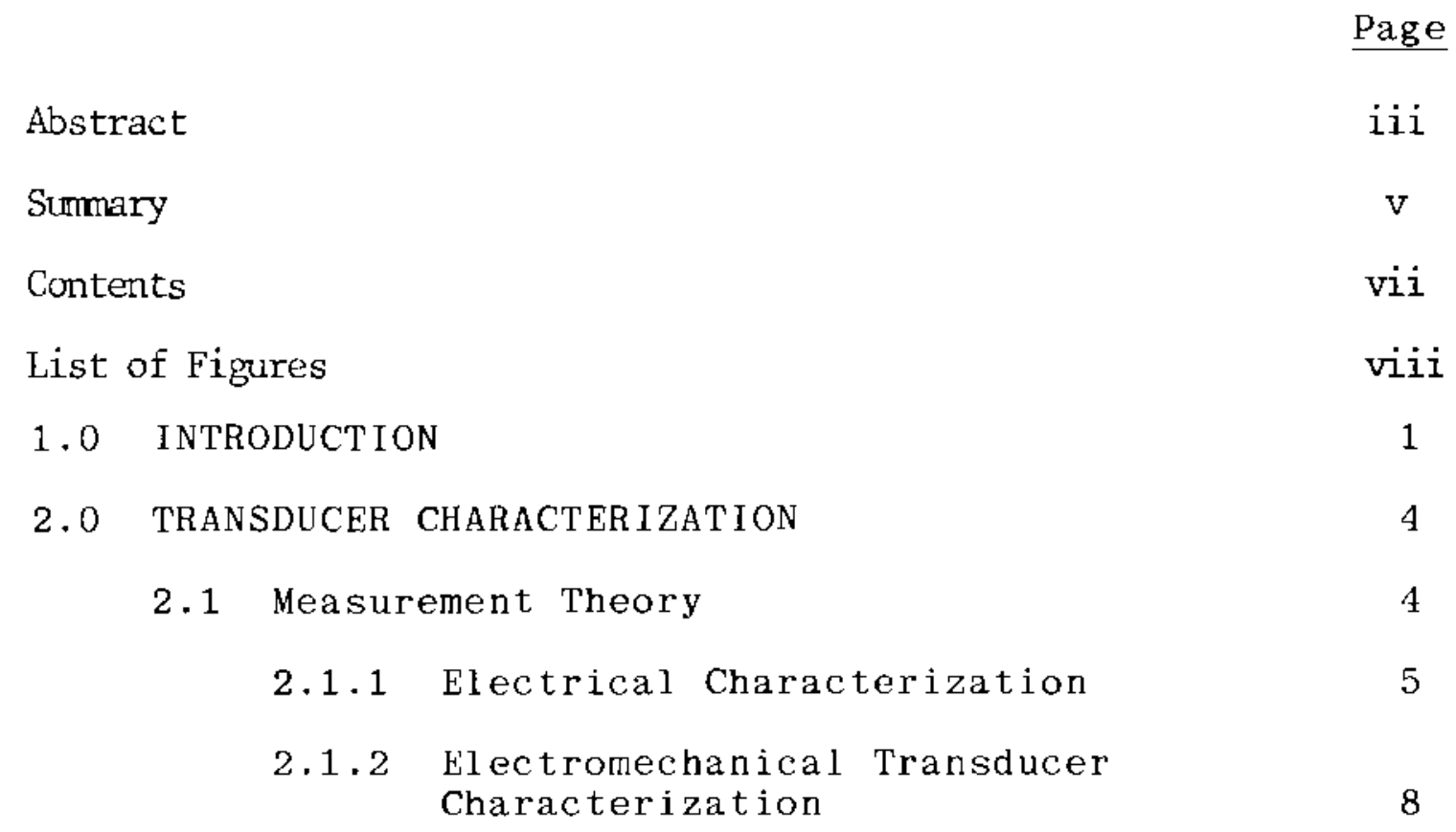

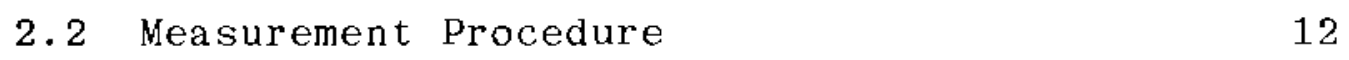

$\begin{array}{lll}2.3 & \text { Beam Pattern Mapping } & 17\end{array}$

3.0 RECEIVER-DISPLAY CHARACTERIZATION 25

3.1 Measurement System 25

3.2 Input Noise and Input Sensitivity
Measurements

$\begin{array}{lll}3.3 & \text { Measurement Results } & 27\end{array}$

3.3.1 Frequency Response Measurements 28

3.3.2 Linearity Measurements 33

4.0 PULSER CHARACTERIZATION 36

5.0 DISCUSSION 42

5.1 Ultrasonic Transducer/Search Unit 42

5.2 Receiver $\rightarrow$ Display Characterization 44

$\begin{array}{lll}5.3 & \text { Pulser } & 44\end{array}$

References $\quad 46$ 
LIST OF FIGURES

$\underline{\text { Page }}$

1. Equivalent Circuit Used to Measure the

Complex Impedance of a Transducer

2. Equivalent Circuit Used to Evaluatc the Efficiency of the Transducer Acting as a

Receiver

3. Block Diagram of the System Used for the Evaluation of the Electrical and Electromechanical Properties of a Transducer

4. Waveform $\left[v_{1}(t)\right]$ Measured with a Reference Load in Place

5. Waveform $\left[v_{2}(t)\right]$ Measured with the Unknown Load Presented by the T'ransducer in Place

6. Complex Electrical lmpedance of the Transducer Calculated from the Two Observed Waveforms, $v_{1}(t)$ and $v_{2}(t)$

7. Transmit Power as a Function of Frequency

8. Waveform $\left[\mathrm{V}_{3}(\mathrm{t})\right]$ Obtained from the Transducer Operating as a Rcceiver

9. Insertion Loss as a Function of Frequency

10. Calibration Block Used to Map the Sound Field Produced by Angled Beam Transducers in Metals

11. Block Diagram of the liectronics of the Sound Field Profiling System

12. Example of the Output of the Sound Field Profiling System

13. Comparison of Beam Profiles Produced by Different-Shaped Transducers

14. Comparison of Bcam Profiles Produced by Different-Shaped Transducers 


\section{LIST OF FIGURES}

$\left(\operatorname{con} t^{\prime} d\right)$

Page

15. Sound Beam Profile produced by a DualElement, Angled Beam Transducer (metal path length: 1.5 in.; operating frequency: $1.5 \mathrm{MHz}$ )

16. Sound Field Produced by a Dual-Filement, Angled Beam Transducer (metal path length:

3 in.; operating frequency: $1.5 \mathrm{MHz}$ )

17. Block Diagram of the Electronics Used to Characterize the Performance of the Receiver-Display

18. Frequency Response of the Receiver-Display Portion of a Commercially Available UT Instrument (Modcl 1)

19. Frequency Response of Model 1 over a Broader Range of Frequencies

20. Frequency Response of a Second Commercially Available UT Instrument (Model 2)

21. Frequency Response of Model 2 over a Broader Range

22. Results of I, inearity Test Upon Model 1

23. Results of Linearity Test Upon Model 2

24. Block Diagram of the System Used to

Characterize the Transmitter of Pulscr

25. Results of Measurements Made Upon the Pulser Subsystem of Model 1

26. Measurements Made Upon Pulser Subsystem of Model 1 with Maximum Damping

27. Calculated Output (Source) Impedance of the Pulser Subsystem of Model 1 for Two Different Damping Settings 


\section{CHARACTERIZATION METHODS FOR ULTRASONIC TEST SYSTEMS}

\subsection{INTRODUCTION}

The need for standardized and reproducible ultrasonic test instrument performance underlies all efforts aimed toward developing reproducible test procedures (Sachse and hsu 1979; O'Donnel1, Busse and Miller, 1980; Lidington and Silk 1972; Papadakis 1977). Here "reproducible" means that results obtained with the instrument must be repeatable from day to day at a given location and also that test procedures can be reproduced at many locations by different personnel. This report presents methods designed to measure the operational characteristics of ultrasonic test instruments. These methods are based largely on automated (i.e., computerized) procedures so that large amounts of data can be accumulated and handled conveniently using a laboratory analysis system. These methods were implemented at Pacific Northwest Laboratory (PNL) to help document the performance characteristics of typical inspection units currently being used in industry. This work supports the program, "Integration of NDE Reliability and Fracture Mechanics," which is sponsored by the $\mathrm{Nu}-$ clear Regulatory Commission. The NRC program was established to determine the reliability of current in-service inspection (ISl) techniques and to develop recommendations that will assure a suitably high inspection reliability. From the basic knowledge of the operational characteristics of availablc ultrasonic test equipment, improved test procedures and equipment specifications can be developed.

Ultrasonic test instruments can be divided into three major subsystems: 1) the transducer, 2) the receiver-display, and 3) the pulser. The characterization methods presented in this document use linear circuit theory to characterize these subsystems individually. 
The ultrasonic transducer and a fixed length of coaxial cable are considered here as a single functional unit. The transducer unit is characterized under experimental conditions closely related to the actual operating conditions of the transducers, e.g., transient pulse excitation and proper mechanical (i.e., acoustic) loading of the transducer front surface. The transducer properties which are measured include the complex electrical impedance of the device, the insertion loss, the relative pulse echo sensitivity, and the bandwidth and center frequency of the unit. The sound field produced by these transducers is also mapped.

The measured properties of the receiver-display subsystem are bandwidth, linearity, input noise and input sensitivity. These properties of the receiver-display may vary as the sensitivity, $r f$ filtering and video filtering of the instrument are varied. Because of the many possible combinations of tunings and adjustments, the receivers are characterized at a limited number of settings. Receiver-display systems with analog outputs that are normally used to drive strip chart recorders can be characterized using an automated measurement system. If no analog outputs are provided, a semiautomated measurement system can be used to record the video display of the instrument. With these two measurement systems it is also possible to compare the video display output with the analog or chart recorder output. In this way, problems with the recorder system can be identified.

The pulser or transmitter subsystem is the most nonlinear component in the ultrasonic test instrument. For this reason, pulser characterization is limited. The pulser properties measured include the frequency spectrum of the highvoltage pulse under different electrical loading conditions and an estimate of the output impedance of the pulser circuit. 
The results of experimental measurements made for several commercially available ultrasonic test instruments and transducers are presented as demonstrations of the testing methods. The results show the utility of the methods proposed for evaluating ultrasonic test systems and also give some insight into the variability found in present test equipment.

The following three sections $(2.0,3.0,4.0)$ describe the test methods and demonstration results for the transducer, receiver-display, and pulser subsystems, respectively. A final section, Section 5.0, discusses the measurements needed to evaluate ultrasonic test system performance. 


\subsection{TRANSDUCER CHARACTERIZATION}

The theory and measurement procedure for evaluating the electrical, electromechanical, and mechanical performance of transducers are presented. The methods used for electrical and electro-mechanical transducer evaluation are based on transicnt electrical excitation of the transducer. Spectrum analysis and application of 1 inear circuit theory then allows the performance parameters, such as complex impedance, insertion loss, bandwidth, and bandwidth center frequency to be measured. The methods presented are generally applicable and can be used to evaluate the performance of many different designs of ultrasonic transducers, $i . e$. , immersion or contact (both angled and normal beam) units. Care must be taken, however, when evaluating these different transducers. For examplc, it is important to maintain the proper mechanical loading of the transducers--immersion transducers must be evaluated in water; contact transducers must be coupled to metal; and angled beam transducers must be operated into a plastic wedge material. Experimental results are presented from transducers of different electrical, mechanical, and acoustic design.

The mechanical evaluation of the transducer is accomplished by mapping the sound field produced by the device. This evaluation is straightforward for immersion transducers (Posakony 1975). A technique is presented for direct mapping of the sound field produced by ang]ed beam transducers in metal (Wuestenberg 1970, 1979).

\subsection{MEASUREMENT THEORY}

The measurement procedurc presented is based on 1 incar transfer functions (Sittig 1967; Sachse and Hsu 1979). Application of linear theory to transducer operation requires simplifying assumptions. First, the analysis is restricted 
to a single mode of operation. In other words, a transducer designed to launch and receive longitudinal elastic waves will not transmit or respond to any other type of elastic wave. Second, a linear system response is assumed. Electrical and acoustic excitation levels are assumed to be small enough that thcy can be adequately described by 1 inear equations of motion. The assumption of "small signal" response is not overly restrictive and is, in fact, the normal mode of operation for ultrasonic transducers.

\subsubsection{Electrical Characterization}

The recommended practice for characterization of the electrical properties of transducers requires that the complex electrical impedance (resistive and reactive components) of the device be measured (ASA 1970). For this measurement, both the voltage and current magnitudes and phases must be measured as a function of frequency. This measurement is generally carried out using a continuous-wave measurement instrument such as a vector impedance bridge. It is also possible to make a similar determination using transient voltage excitation and signal processing techniques (Sachse). Figure 1 describes the two-step measurement process for determining the complex impedance of an unknown load, $\tilde{Z}_{\ell}$.

In Step 1 the transient voltage, $v_{1}(t)$, is recorded by means of a transient waveform recorder or sampling scope. From this time domain signal, the complex Fouricr transform is calculated:

$$
\tilde{V}_{I}(\omega)=\int_{-\infty}^{\infty} v_{1}(t) e j \omega t d t .
$$

In practice, this Fourier transformation is performed using a Fast Fourier Transform subroutine in a microcomputer. In the 

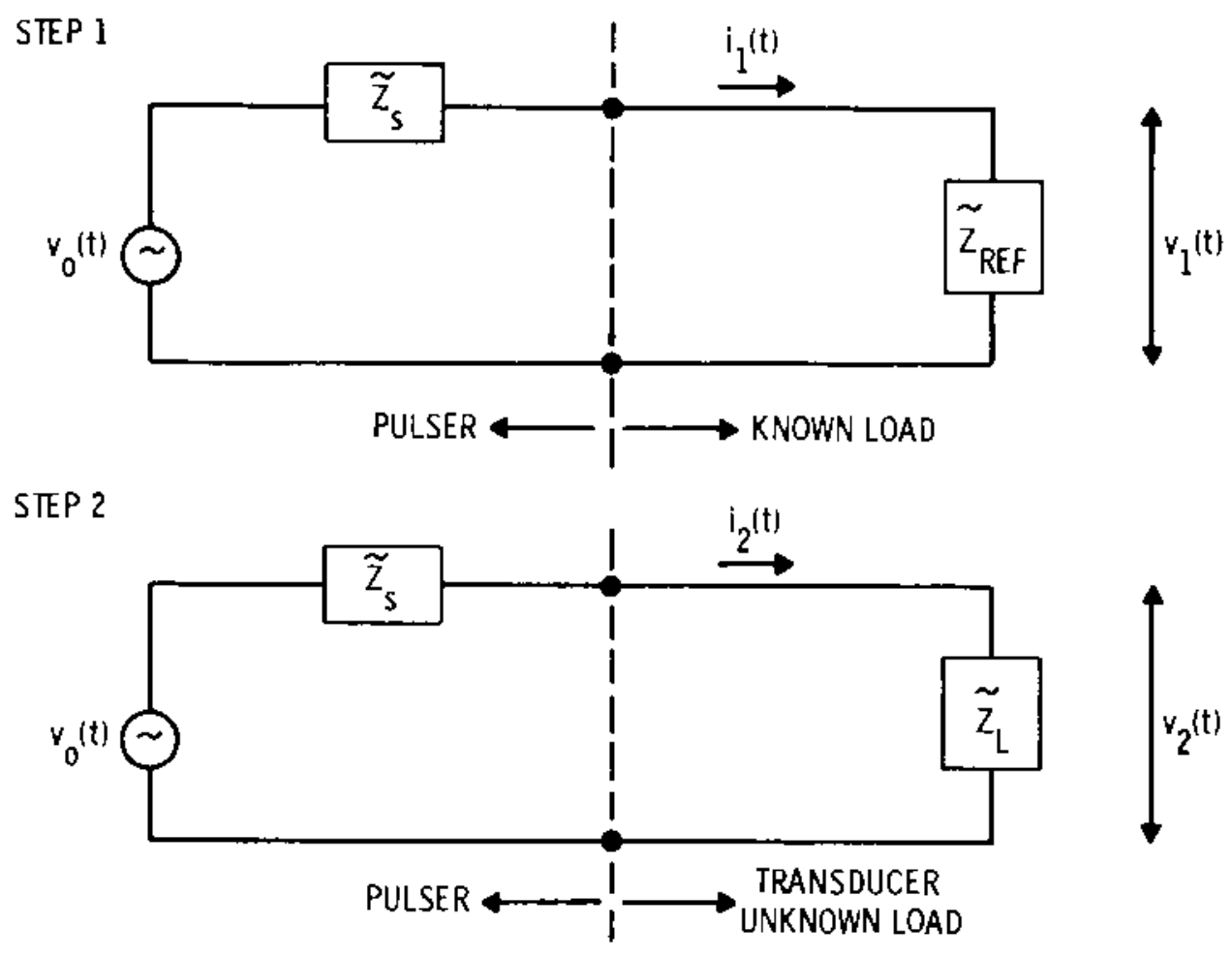

Figure 1. Equivalent Circuit Used to Measure the Complex
Impedance of a Transducer

following equations the convention is that all capitalized variables are complex (have roal and imaginary parts) and are functions of frequency. The voltage divider formed by $\mathrm{z}_{\mathrm{R} F F}$ and $\mathrm{Z}_{\mathrm{S}}$ allows the calculation of $\mathrm{V}_{\mathrm{O}}$ :

$$
v_{0}=\frac{Z_{R E F}+Z_{S}}{Z_{R E F}} v_{1}
$$

A signal generator with a known output impedance $\left[Z_{S}=(50+\right.$ jo) ohms] and a known reference load $\left[Z_{\mathrm{REF}}=(50+\right.$ jo) ohms is used, so

$$
\mathrm{v}_{\mathrm{O}}=2 \mathrm{v}_{1}
$$


Step 2 again involves recording a transient voltage, $v_{2}(t)$, where now the reference load has been replaced with the unknown electrical load, $Z_{L}$. This unknown load represents the ultrasonic transducer and an appropriate length of coaxial cable. The Fourier transform of $v_{2}(t)$ is again related to $v_{0}(t)$ by the voltage divider:

$$
\mathrm{v}_{2}=\frac{\mathrm{Z}_{\mathrm{L}}}{\mathrm{Z}_{\mathrm{S}}+\mathrm{Z}_{\mathrm{L}}} \mathrm{v}_{\mathrm{o}}=\frac{2 \mathrm{Z}_{\mathrm{L}} \mathrm{v}_{1}}{\mathrm{Z}_{\mathrm{S}}+\mathrm{Z}_{\mathrm{L}}}
$$

Now, calculating $Z_{L}$ is a matter of algebra:

$$
\mathrm{Z}_{\mathrm{L}}=\frac{\mathrm{v}_{2}}{\left(2 \mathrm{v}_{1}-\mathrm{v}_{2}\right)} \mathrm{Z}_{\mathrm{S}}
$$

For this method to work properly, some care must be exercised in the choice of the transient waveform $v_{0}(t)$. The magnitude of the transform pair of this signal $\left(\left|v_{0}\right|\right)$ should have rcasonable amplitude over the entire frequency range of interest. A square wave pulse of duration $\tau$, where $\tau$ is less than one over the maximum frequency of interest, is sufficient for this purpose. The maximum frequency of interest is generally greater than twice the center frequency of the transducer.

Once the complex electrical impedance of the load has been determined, it is possible to calculate other useful electrical parameters such as the electrical power delivered to the transducer, $\mathrm{P}_{\mathrm{T}}$ :

$$
\mathrm{P}_{\mathrm{T}}=\frac{1}{2} \operatorname{Re}\left[\mathrm{I}_{2}^{*} \mathrm{x} \mathrm{v}_{2}\right]=\operatorname{Re}\left[\mathrm{Z}_{\mathrm{L}}\right] \frac{\left|\mathrm{V}_{2}\right|^{2}}{2\left|\mathrm{Z}_{\mathrm{L}}\right|^{2}}
$$

Here "Re" refers to taking the real part of the quantity in brackets. 


\subsubsection{Electromechanical Transducer Characterization}

Electromechanical efficiency refers to the efficiency of the transducer for converting electrical to mechanical energy and the inverse process.

It is generally accepted that piezoelectric transducers operating into a fluid medium are reciprocal devices. The term reciprocal has many interpretations (Foldy and Prinakoff 1945; Primakoff and Foldy 1947; MacLean 1940; Carstensen 1947; Sabin 1964; Reid 1974); however, here the 1 imited statement of reciprocity--the efficiency of the piezoelectric element as a transmitter is equal to the efficiency of the device as a receiver--is assumed.

Measurement of insertion loss combined with assumptions of reciprocity provides a means for determining the electromechanical efficiency of a transducer. The two-way insertion loss is defined as the ratio of the available electrical power generated by the transducer as a receiver to the elcctrical power dissipated in the device as a transmitter. The acoustic wave produced in the transmit mode is assumed to propagate without loss, reflect from a perfectly reflecting interface, and be received by the same transducer.

As seen in Section 2.1.1, Equation (6), knowledge of the complex impedance, $\mathrm{Z}_{\mathrm{L}}$, of the transducer and the complex spectra of the transmit waveform $V_{2}$ allows the calculation of $\mathrm{P}_{\mathrm{T}}$, the electrical power dissipated in the transducer in the transmit mode. Now consider the receive mode, described in Figure 2. Operating as a receiver, the piezoelectric action of the crystal can be represented as a voltage source in series with $Z_{L}$, the complex impedance of the transducer. This simple circuit must now drive the load presented to it by the pulser circuit (in this example, a 50-ohm resistive load). By Fourier transforming the observed voltage waveform 


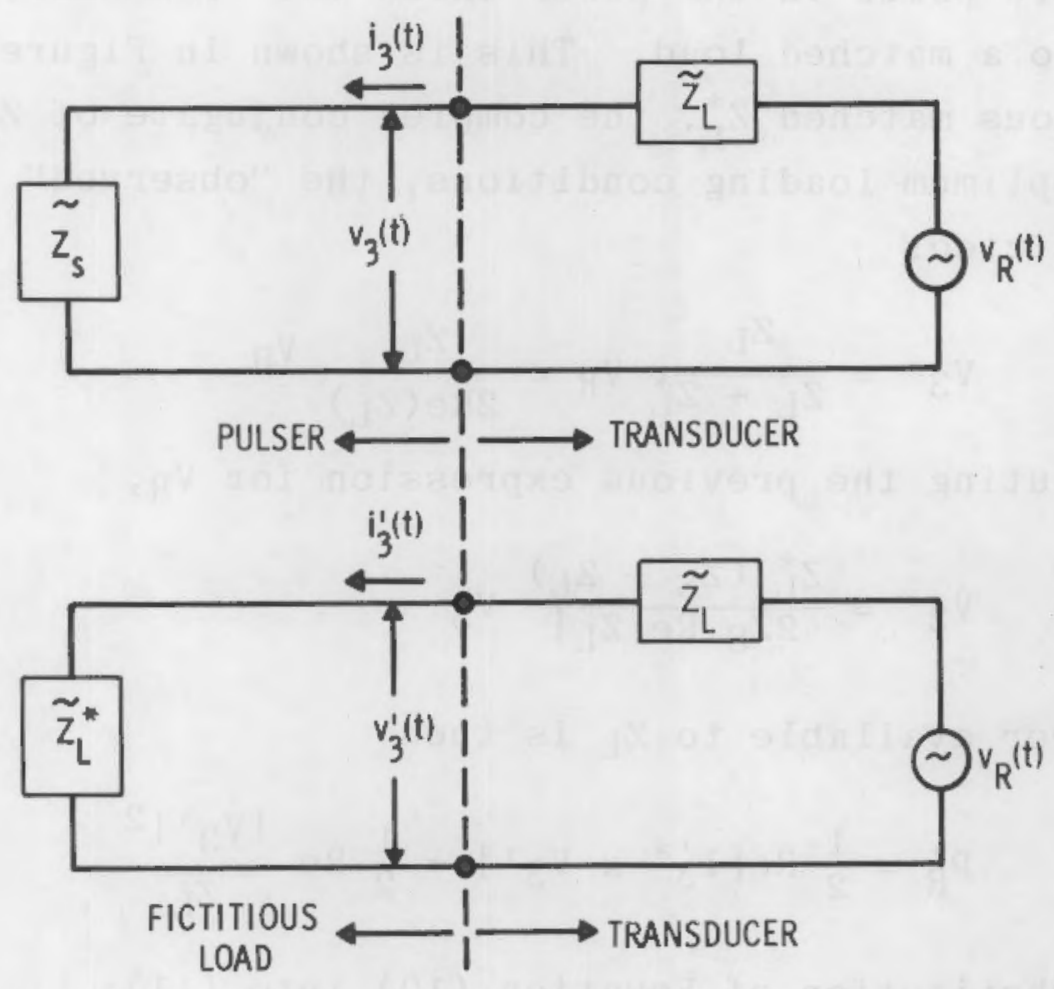

Figure 2. Equivalent Circuit Used to Evaluate the Efficiency of the Transducer Acting as a Receiver

$v_{3}(t)$, the observed power delivered to the load in the receive mode can be calculated.

$$
P_{R}=\frac{1}{2} \operatorname{Re}\left[I_{3}^{*} V_{3}\right]=\operatorname{Re}\left[Z_{S}\right] \frac{\left|V_{3}\right|^{2}}{2\left|Z_{S}\right|^{2}}
$$

The observed insertion loss is then simply the ratio of $P_{R}$ to $\mathrm{P}_{\mathrm{T}}$. Similarly, the spectrum of the equivalent source voltage can be determined:

$$
\mathrm{v}_{\mathrm{R}}=\left(1+\frac{\mathrm{z}_{\mathrm{L}}}{\mathrm{z}_{\mathrm{S}}}\right) \mathrm{v}_{3}
$$

In order to determine the ideal insertion loss, the available power generated by the transducer must be calculated. The 
available power is the power which the transducer would deliver to a matched load. This is shown in Figure $2 \mathrm{~B}$ as a fictitious matched $\mathrm{Z}_{\mathrm{L}}^{*}$, the complex conjugate of $\mathrm{Z}_{\mathrm{L}}$. Under these optimum loading conditions, the "observed" voltage can be predicted:

$$
\mathrm{v}_{3^{\prime}}=\frac{\mathrm{z}_{\mathrm{L}}}{\mathrm{Z}_{\mathrm{L}}+\mathrm{z}_{\mathrm{L}}^{*}} \mathrm{v}_{\mathrm{R}}=\frac{\mathrm{z}_{\mathrm{L}}}{2 \operatorname{Re}\left(\mathrm{Z}_{\mathrm{L}}\right)} \mathrm{v}_{\mathrm{R}}
$$

Substituting the previous expression for $V_{R}$,

$$
v_{3^{\prime}}=\frac{z_{L}^{*}\left(z_{S}+z_{L}\right)}{2 z_{S} \operatorname{Re}\left[z_{L}\right]} v_{3}
$$

The power available to $z_{L}$ is then

$$
\mathrm{P}_{\mathrm{R}}^{\prime}=\frac{1}{2} \operatorname{Re}\left[\mathrm{I}_{3}^{\prime *} \times \mathrm{V}_{3}{ }^{\prime}\right]=\frac{1}{2} \operatorname{Re} \frac{\left|\mathrm{V}_{3}{ }^{\prime}\right|^{2}}{\mathrm{Z}_{\mathrm{L}}}
$$

Upon substitution of Equation (10) into (11):

$$
P_{R}^{\prime}=P_{R} \frac{\left(z_{L}^{*}+z_{S}\right)\left(z_{L}+z_{S}\right)}{\left(z_{L}+z_{L}^{*}\right)\left(z_{S}+z_{S}^{*}\right)}
$$

In other words, the available power $P_{R}^{\prime}$ can be calculated from the measured power $P_{R}$ if $Z_{L}$, the impedance of the transducer, is known. The available power is equal to the measured power when the transducer impedance equals the output impedance, $\mathrm{Z}_{\mathrm{S}}$, of the pulser circuit.

It is now possible to evaluate the ideal insertion loss and hence the electromechanical efficiency, $\eta$, of the transducer .

$$
\text { Insertion Loss }=\eta^{2}=\frac{P_{R}^{\prime}}{P_{T}}
$$

where $P_{T}$ is defined by Equation (6) and $P_{R}^{\prime}$ is defined by Equation (12). For some transducers, it is difficult to 
determine ideal insertion loss because of numerical anomalies which occur in the calculation of $\mathrm{P}_{\mathrm{R}}^{\prime}$. In these situations, the simple ratio of $\mathrm{P}_{\mathrm{R}}$ to $\mathrm{P}_{\mathrm{T}}$ must be used.

Other means for characterizing the efficiency have been proposed. For example, in a swept frequency sinusoidal measurement (Erikson 1979) the relative loop sensitivity of the transducer has been defined as the ratio of the observed receive voltage to the loaded transmitter voltage at the center frequency of the transducer. The information needed for calculating relative loop sensitivity (and other indices of transducer performance) are present in the proposed transient calibration technique and can be extracted with appropriate algebraic manipulation.

For example, the loaded transmitter voltage $\mathrm{V}_{\mathrm{T}}^{\mathrm{L}}$ can be calculated from the ratio of the power spectral amplitudes of $\mathrm{V}_{2}$ and $\mathrm{V}_{1}$

$$
\left|\mathrm{v}_{\mathrm{T}}^{\mathrm{L}}\right|=\left|\mathrm{v}_{2}\right| /\left|\mathrm{v}_{1}\right|
$$

This normalization is necessary to simulate an unload transmitter drive voltage that is frequency independent. The relative pulse echo sensitivity, expressed in $d B$, is then just

$$
20 \log \left(\frac{\left|v_{3}\right|}{\left|\frac{v_{2}}{}\right|}\right)
$$

The value of $\mathrm{S}_{\mathrm{rel}}$ is established at the bandwidth center frequency.

The pulse echo sensitivity calculated in this way is a function of the ultrasonic frequency, and so measurement of useful transducer bandwidth, center frequency, and other performance parameters can be based on this curve. 


\subsection{MEASUREMENT PROCEDURE}

The basic block diagram of the system used to gather the necessary data for transducer characterization is shown in Figure 3. The pulser used at PNL consists of a pulse generator capable of producing a 50-volt pulse across a 50-ohm load. A transient recorder with a high-impedance active probe is used to record the transient waveforms, and a microcomputer is used for control and the signal processing functions described in the previous section.

\section{U.T. INSTRUMENT - TRANSDUCER TEST}

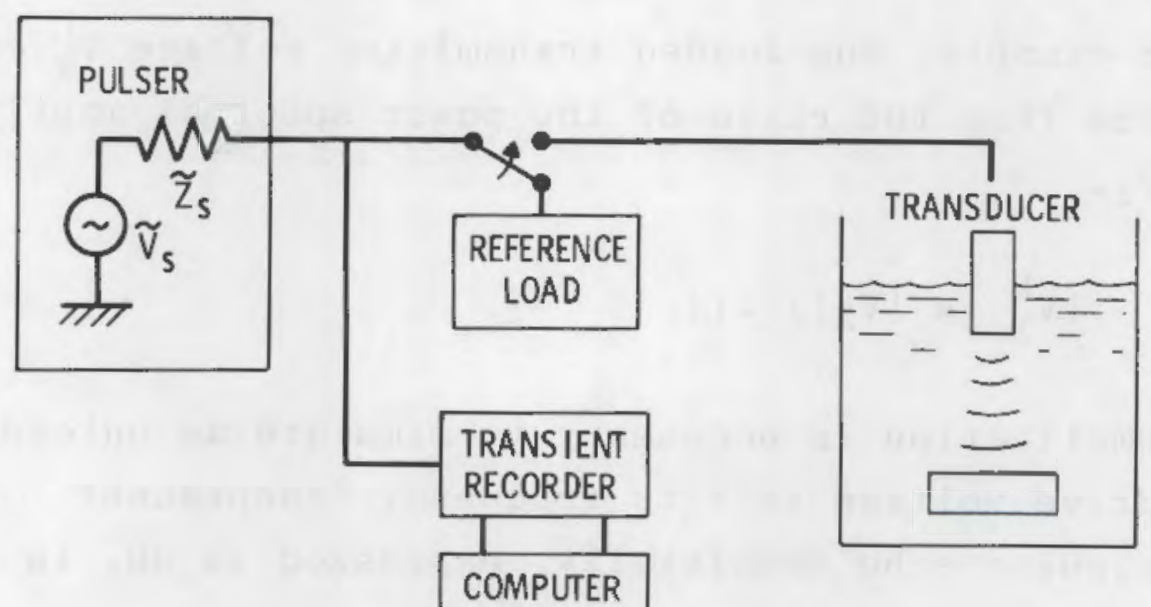

Figure 3. Block Diagram of the System Used for the Evaluation of the Electrical and Electromechanical Properties of a Transducer

For the measurement procedure three different voltage waveforms are recorded experimentally. The first is shown in Figure 4. It is a record of the drive voltage supplied by the pulser into a known and well characterized load-- $(50+$ j0) ohms. The pulse width is determined by the operating frequency of the transducer, and the polarity is chosen to 


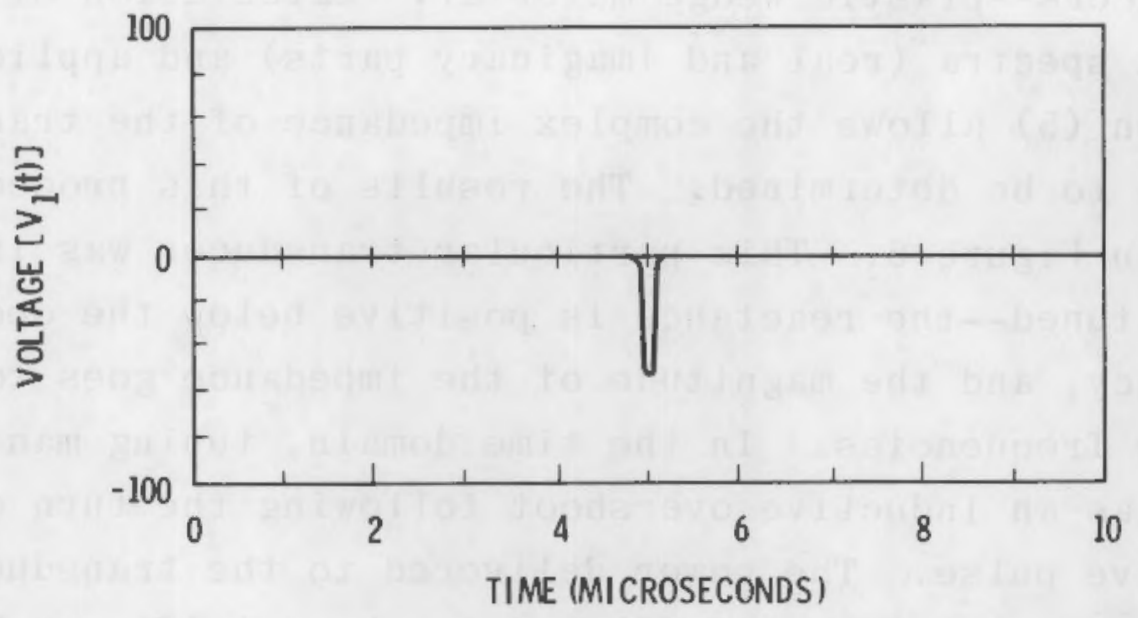

Figure 4. Waveform $\left[V_{1}(t)\right]$ Measured with a Reference Load in Place

maintain the convention used in most ultrasonic test equipment. The second waveform recorded is shown in Figure 5 . It is obtained by removing the reference load and applying the unknown load; the transducer, loaded by an appropriate mechanical load. For immersion transducers, the appropriate load is water, for contact transducers--metal, and for angled beam

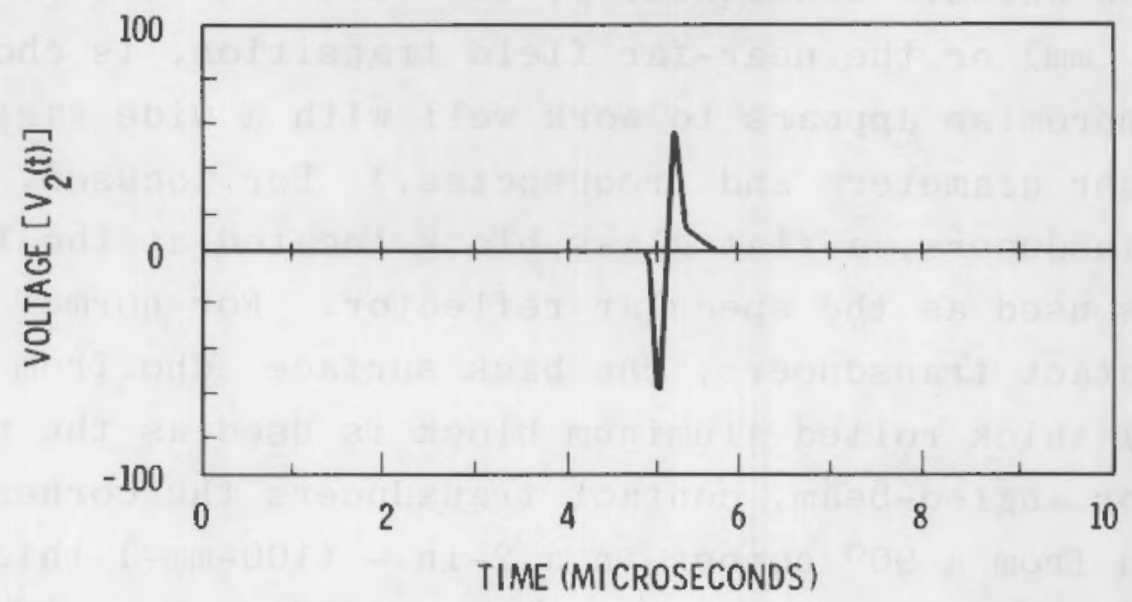

Figure 5. Waveform $\left[V_{2}(t)\right]$ Measured with the Unknown Load Presented by the Transducer in Place 
transducers--plastic wedge material. Calculation of the complex spectra (real and imaginary parts) and application of Equation (5) allows the complex impedance of the transducer element to be determined. The results of this procedure are shown in Figure 6. This particular transducer was inductively tuned--the reactance is positive below the operating frequency, and the magnitude of the impedance goes to zero at the low frequencies. In the time domain, tuning manifests itself as an inductive overshoot following the turn off of the drive pulse. The power delivered to the transducer is calculated with Equation (6) and is shown in Figure 7 .

The third waveform recorded is that of a receive echo obtained from a large specular reflector. For nonfocused, immersion transducers a flat, smooth glass block, not smaller than 3 in. by $3 \mathrm{in}$. ( $75 \mathrm{~mm}$ by $75 \mathrm{~mm}$ ) by $1-\mathrm{in}$. (25-mm) thick is used. This reflector is placed $2 \mathrm{in.}(50 \mathrm{~mm})$ from the face of the transducer. (Ideally, the reflector is placed at the near to far field transition $\left(\mathrm{a}^{2} / \lambda\right)$ for the transducer being tested. However, this is impractical for many types of immersion units. Consequently, the lesser distance, either 2 in. (50 mm) or the near-far field transition, is chosen. This compromise appears to work well with a wide variety of transducer diameters and frequencies.) For focused, immersion transducers, a flat glass block located at the focal plane is used as the specular reflector. For normal (straight) beam contact transducers, the back surface echo from a 2-in.(50-mm-) thick rolled aluminum block is used as the reflector. For angled-beam, contact transducers the corner reflection from a $90^{\circ}$ corner in a $2-i n .-(100-m m-)$ thick rolled al uminum block is used as the perfect reflector. Figure 8 shows the results of such a measurement. Panel A) shows the time domain waveform and panel B) shows the relative pulse echo sensitivity. Figure 9 shows the measured and ideal 


\section{MAGNITUDE OF \\ IMPEDANCE (ohms) \\ REACTANCE (ohms) RESISTANCE (ohms)}

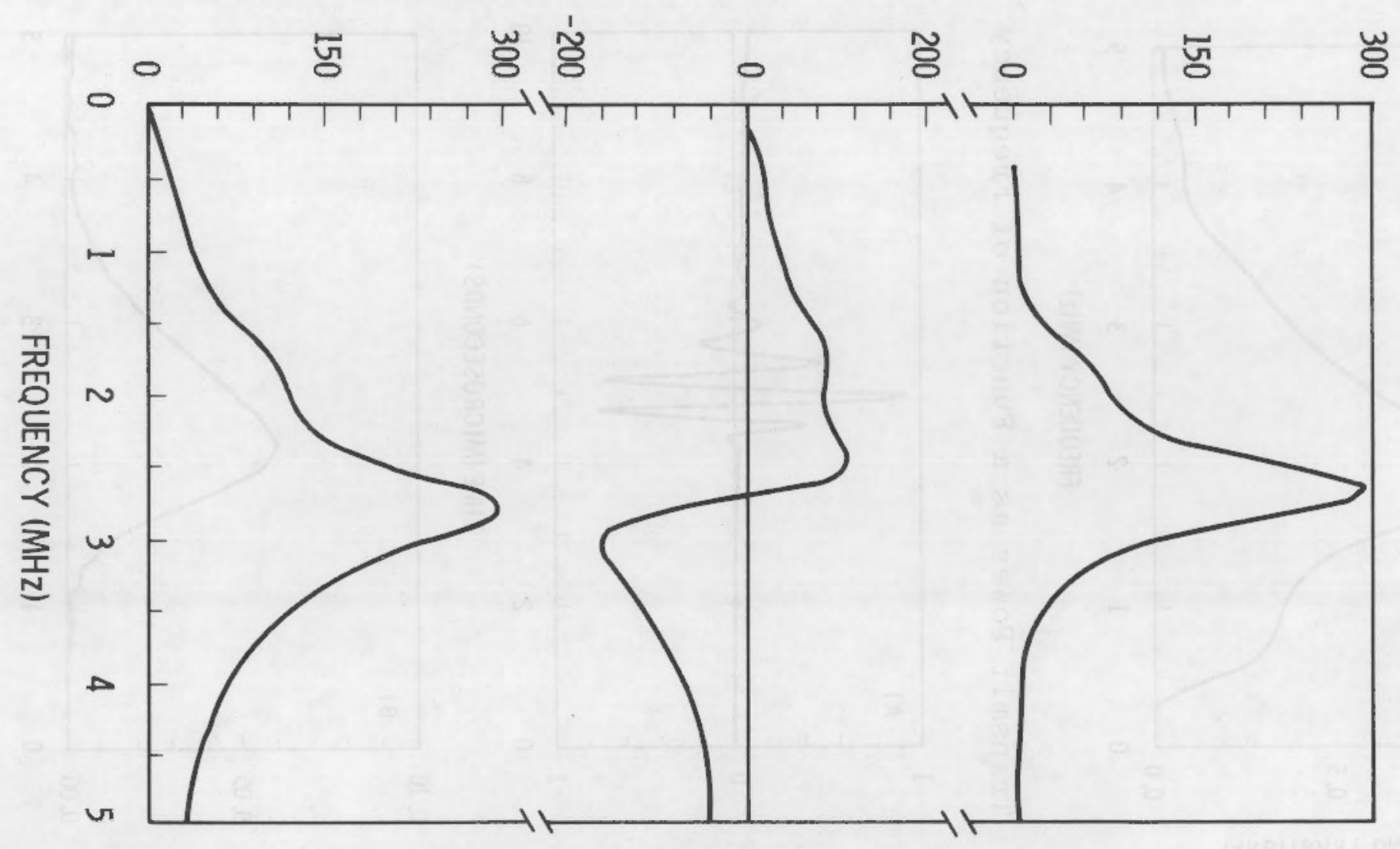

Figure 6. Complex Electrical Impedance of the Transducer Calculated from the Two Observed Waveforms, $v_{1}(t)$ and $V_{2}(t)$ 


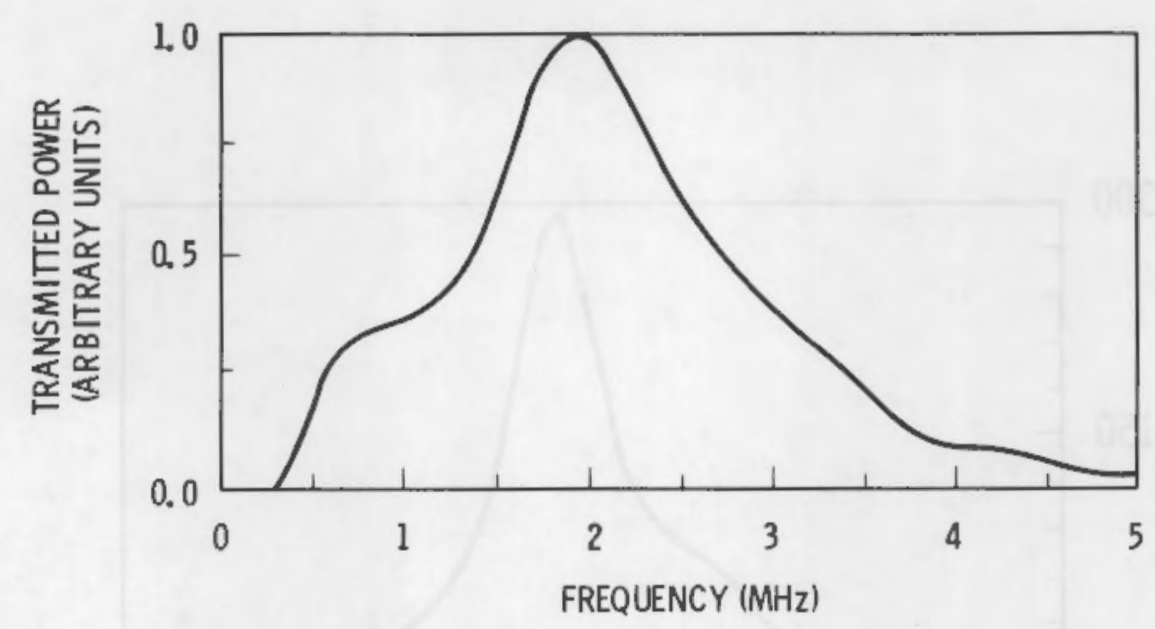

Figure 7. Transmit Power as a Function of Frequency
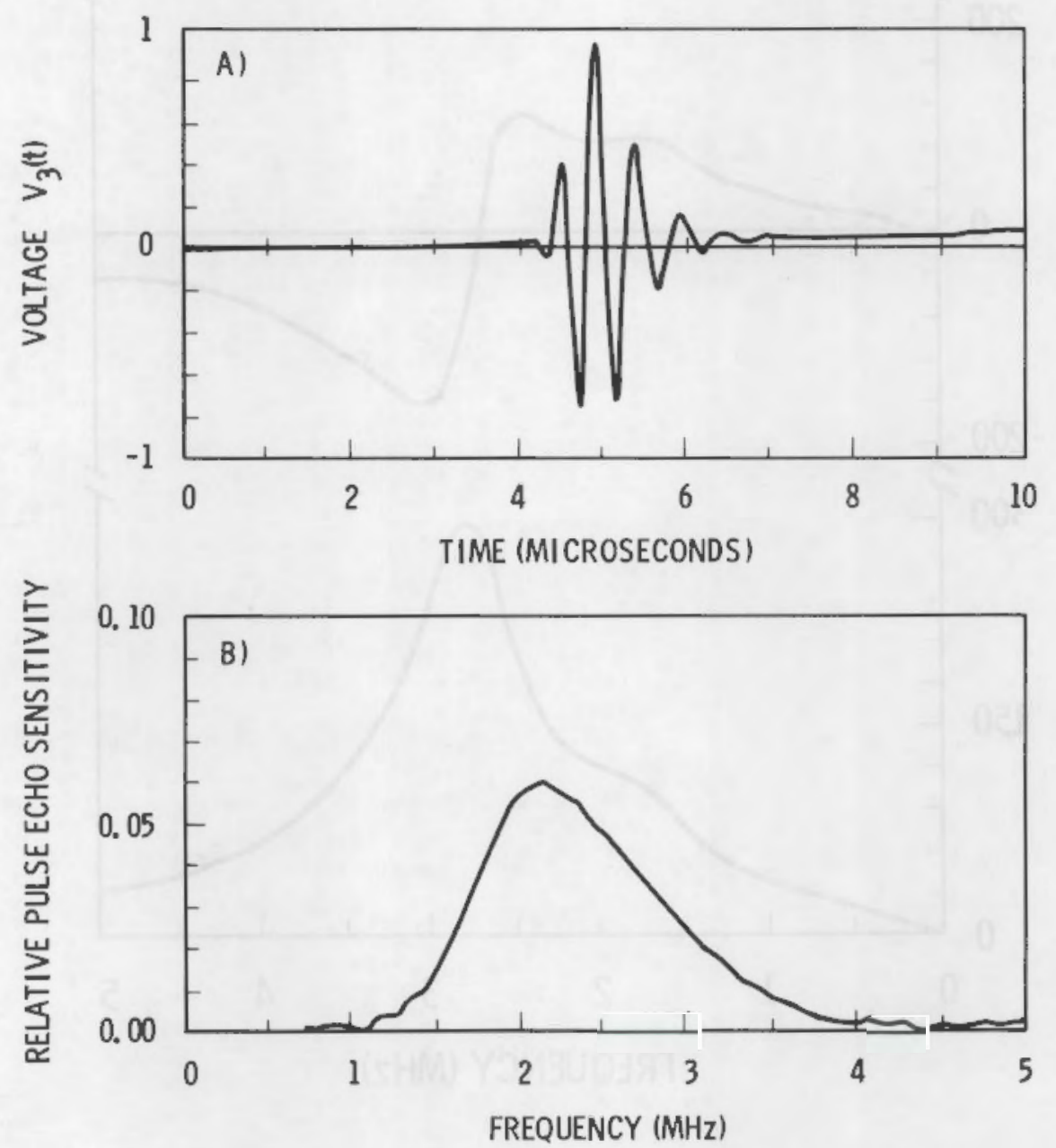

Figure 8. Waveform $\left[V_{3}(t)\right]$ Obtained from the Transducer Operating as a Receiver 


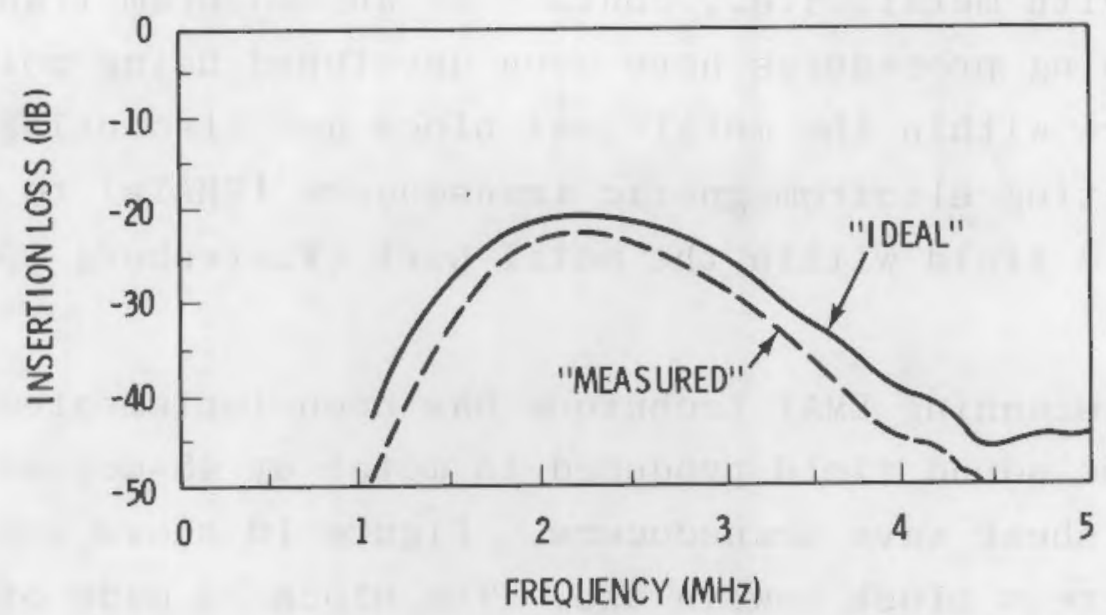

Figure 9. Insertion Loss as a Function of Frequency

insertion loss expressed in decibels after application of the analysis presented in the previous section.

This particular transducer was designed to produce a $45^{\circ}$, vertically polarized shear wave in steel, through the use of a plastic shoe. This unit was characterized with the plastic shoe in place using the corner reflection in the aluminum test block. It is essential to characterize angledbeam transducers with the plastic shoe in place because many transducers of this design employ "matching layers" on the face of the piezoelectric elements which are specifically designed to operate into plastic.

\subsection{BEAM PATTERN MAPPING}

The mapping of the ultrasonic field pattern produced by a transducer is also important for complete performance evaluation. For immersion transducers, such beam pattern mapping is usually accomplished in a water tank by scanning a point1 ike receiver or reflector through the ultrasonic beam and recording the transmitted or reflected signal (Papadakis 
1977; Posakony 1975). For transducers meant to be used in contact with metal, i.e., contact or angled-beam transducers, beam mapping procedures have been developed using point-like reflectors within the metal test block and also using small, noncontacting electromagnetic transducers (EMATS) to map the ultrasonic field within the metal part (Wuetenberg 1970, 1979).

The scanning EMAT technique has been implemented at PNL to map the sound field produced in metal by 45 -degree and 60degree, shear wave transducers. Figure 10 shows schematically the test block now in use. The block is made of A533 steel and has been machined to have a flat top surface with angled sides. The angled side surfaces were machined at

\section{TRANSDUCER SOUND FIELD PROFILING}

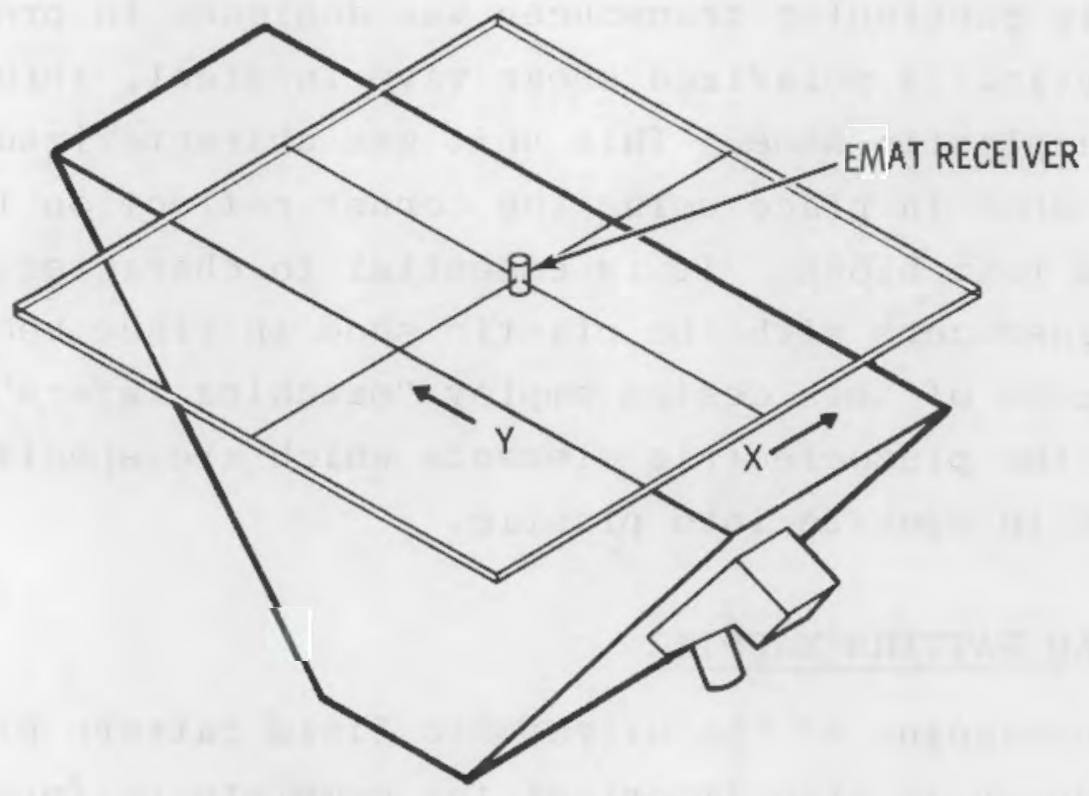

Figure 10. Calibration Block Used to Map the Sound Field Produced by Angled Beam Transducers in Metals 
angles of $30^{\circ}$ and $45^{\circ}$, respectively, with respect to vertical. These angles were chosen so that $60^{\circ}$ and $45^{\circ}$ shear wave transducers would produce a sound field that would be incident at right angles upon the upper surface of the block. By scanning the EMAT in a "raster" fashion over the top surface, a two-dimensional profile of the transducer sound field pattern is obtained. This procedure can be repeated for a number of different metal paths to more completely characterize the beam spreading or focusing properties of the transducer under test.

Figure 11 shows a block diagram of the electronics associated with this system. The ultrasonic and the scanner

\section{SOUND FIELD PROFILING SYSTEM}

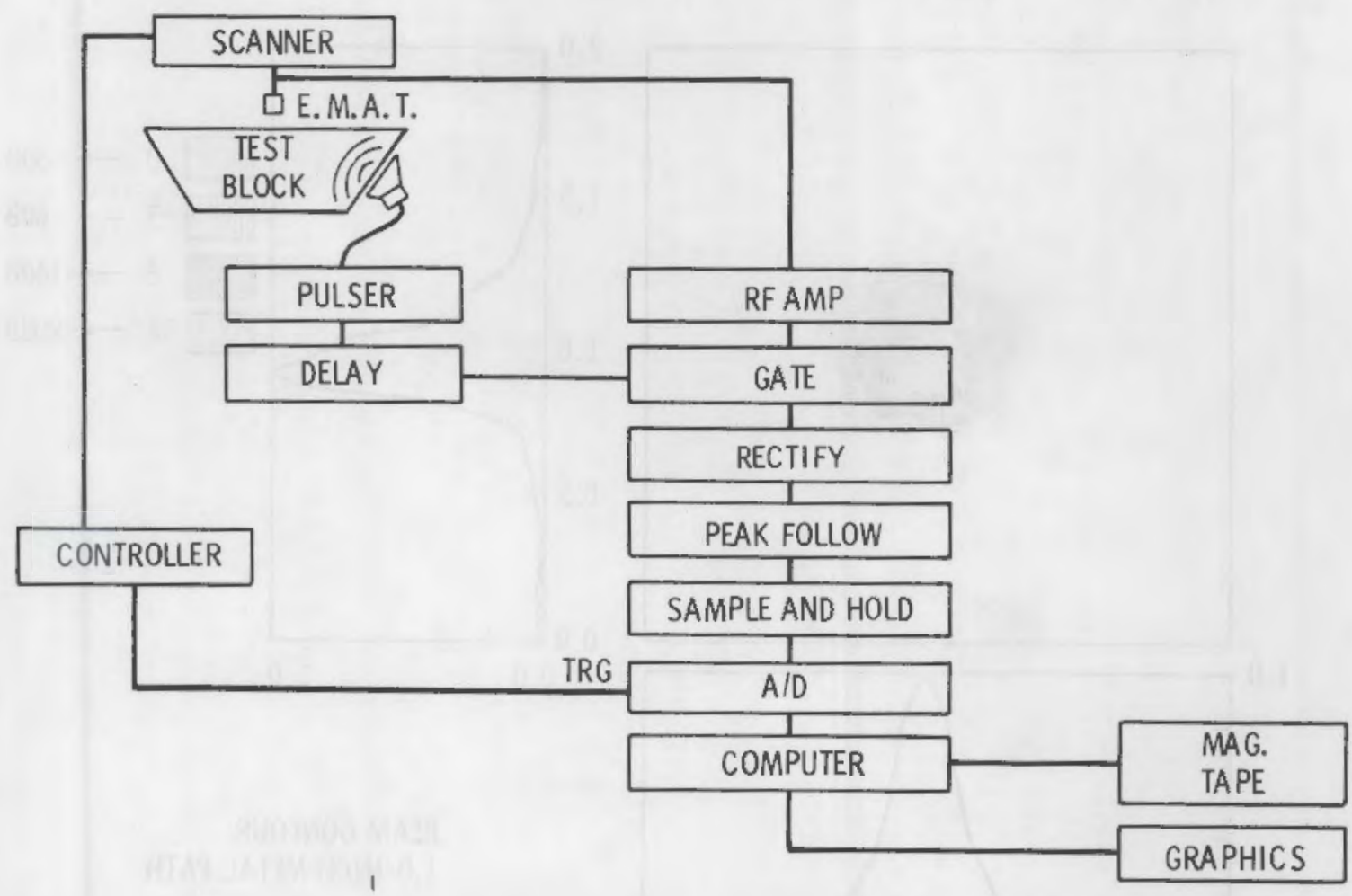

Figure 11. Block Diagram of the Electronics of the Sound Field Profiling System 
systems are basically separate systems which run independently and are simultaneously monitored by the computer. The output of the ultrasonic system is a DC voltage which represents the amplitude of the ultrasonic pulse sensed by the EMAT probe. The output of the scanner system is a train of pulses which are derived from the pulses used to drive the stepper motors of the scanner. These pulses act to trigger the analog-to-digital converter. This scheme for data collection works well as long as the ultrasonic repetition rate is greater than the rate at which trigger pulses are sent to the A/D converter. At present, measurements are made over a $2-i n$. by $2-i n$. ( $50-\mathrm{mm}$ by $50-\mathrm{mm})$ aperture with one measurement every $0.024 \mathrm{in} .(0.6 \mathrm{~mm})$. This results in the generation of nearly 6900 data points for each beam profile. This data is recorded on magnetic tape for permanent record and subsequent re-display. Figure 12 is an example of this beam profile

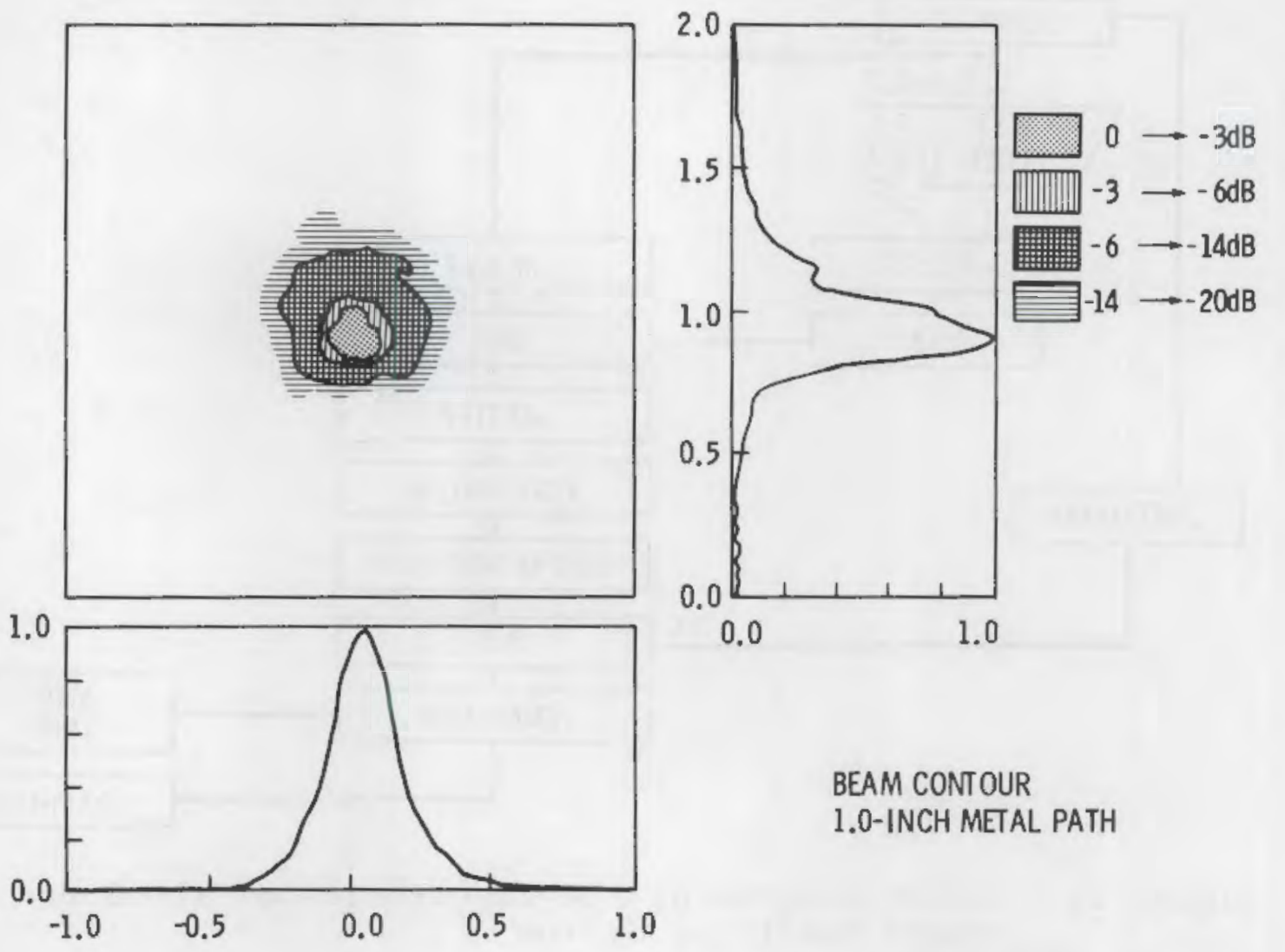

Figure 12. Example of the Output of the Sound Field Profiling System 
data. A contour map is produced as well as two linear "scan line" plots through the maximum of the contour map. The original presentation of the beam profile data is done in color with contour levels chosen as follows: 0 to $-3 \mathrm{~dB},-3$ to $-6 \mathrm{~dB},-6$ to $-14 \mathrm{~dB}$, and -14 to $-20 \mathrm{~dB}$. Other contour levels can be chosen when the data is re-displayed. The $x$ scan direction corresponds to lines of constant metal path within the test block and the $y$ scan direction corresponds to lines with variable metal path (see Figure 10 for detail).

Figure 13 presents the results of measurements made using two different 2.25-MHz transducers with a $1-i n$. metal path distance. Panel A of the figure shows the beam produced by a $1 / 2-i n$. by $1 / 2-i n$. (12.5-mm by $12.5-\mathrm{mm})$ square transducer, and panel B shows the beam produced by a $1 / 2-\mathrm{in}$. (12.5-mm) circular transducer. Figure 14 shows data taken from these same transducers when the metal path is increased to 3.0 inches.

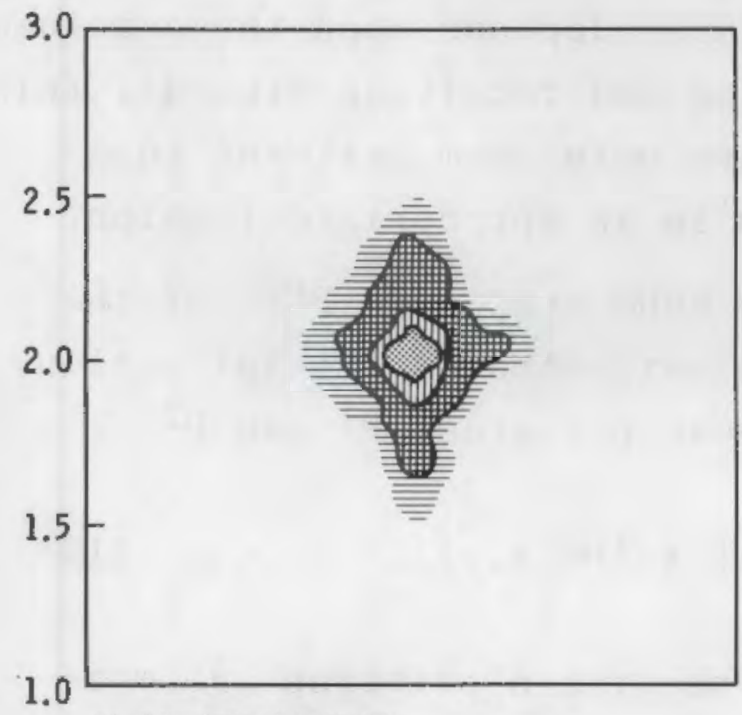

A) SQUARE ELEMENT

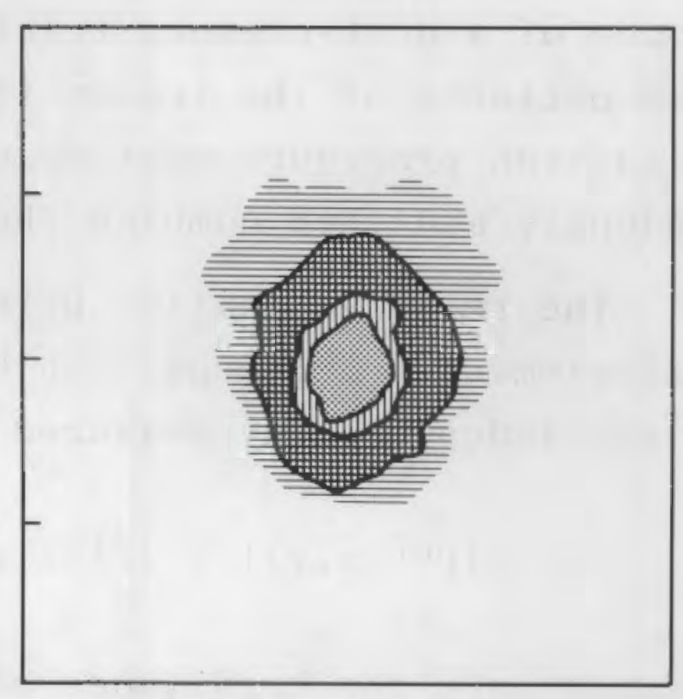

B) ROUND ELEMENT

Figure 13. Comparison of Beam Profiles Produced by DifferentShaped Transducers. 


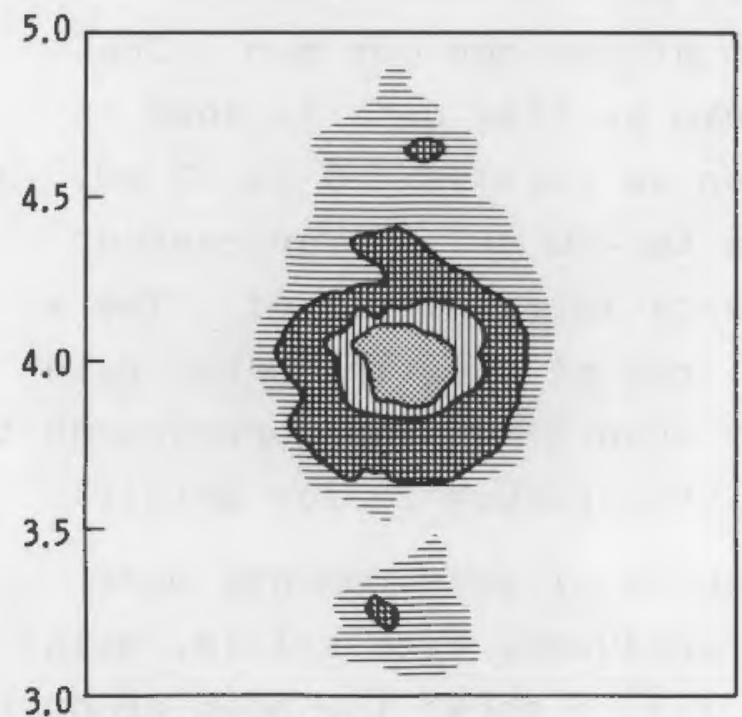

A) SQUARE ELEMENT

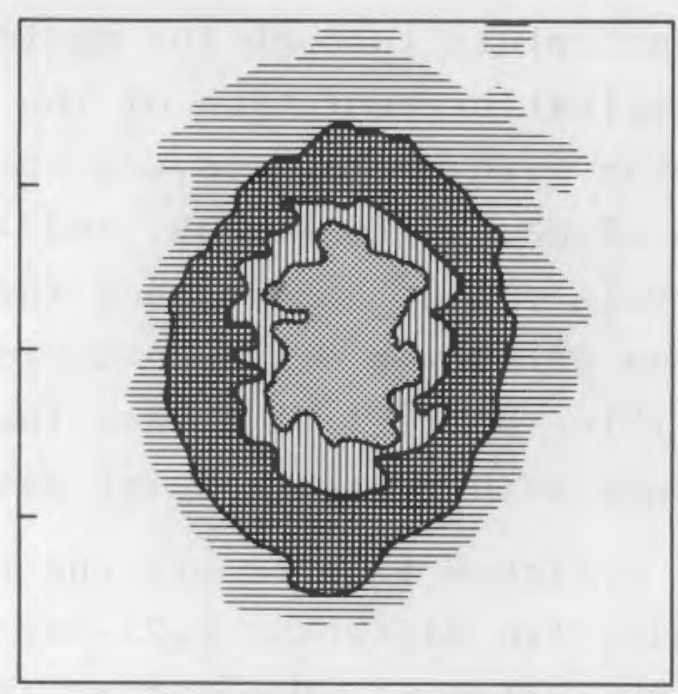

B) ROUND ELEMENT

Figure 14. Comparison of Beam Profiles Produced by DifferentShaped Transducers

PNL has formulated a procedure for the evaluation of dual-element search units. Since the overall transducer response of a dual-element transducer depends upon the combined beam patterns of the transmitting and receiving element, this evaluation procedure must measure both beam patterns independently and then combine them in an appropriate fashion.

The relative spatial pulse echo response ( $\mathrm{P} P E)$ of the dual-element search unit can be estimated by multiplication of the independently measured beam patterns, $\mathrm{P}^{1}$ and $\mathrm{p}^{2}$ :

$$
\left|\mathrm{P}^{\mathrm{pE}}(\mathrm{x}, \mathrm{y})\right|=\left|\mathrm{p}^{1}(\mathrm{x}, \mathrm{y})\right| \mathrm{x}\left|\mathrm{P}^{2}(\mathrm{x}, \mathrm{y})\right| \text {. }
$$

Because only the magnitudes of the field patterns are measured, $\left|\mathrm{p}^{1}\right|$ and $\left|\mathrm{P}^{2}\right|$, no interference effects are produced by forming this product. This seems to be a fair representation of the combined beam pattern because the physical "fields" from the two different transducers are not simultaneously present and therefore cannot interfere with one another. 
This method of combining the two beams allows the spatial response of the transducer to be estimated as if the transducer had been scanned past a point-like reflector in the metal. Figure 15 shows this pulse echo beam pattern near the overlap region of the two beams, $\mathrm{p}^{1}$ and $\mathrm{p}^{2}$, and Figure 16 shows the beam pattern for a metal path of 3.0 inches. The three plots shown in the horizontal scan lines are 1) individual profile from the right element (dotted line), 2) individual profile from the left element (dashed 1 ine), and 3 ) multiplied profile (solid line). The curves have been normalized with respect to the multiplied profile. The 3-dB beam width of the dual-element transducer is seen to increase somewhat when the metal path distance is doubled;
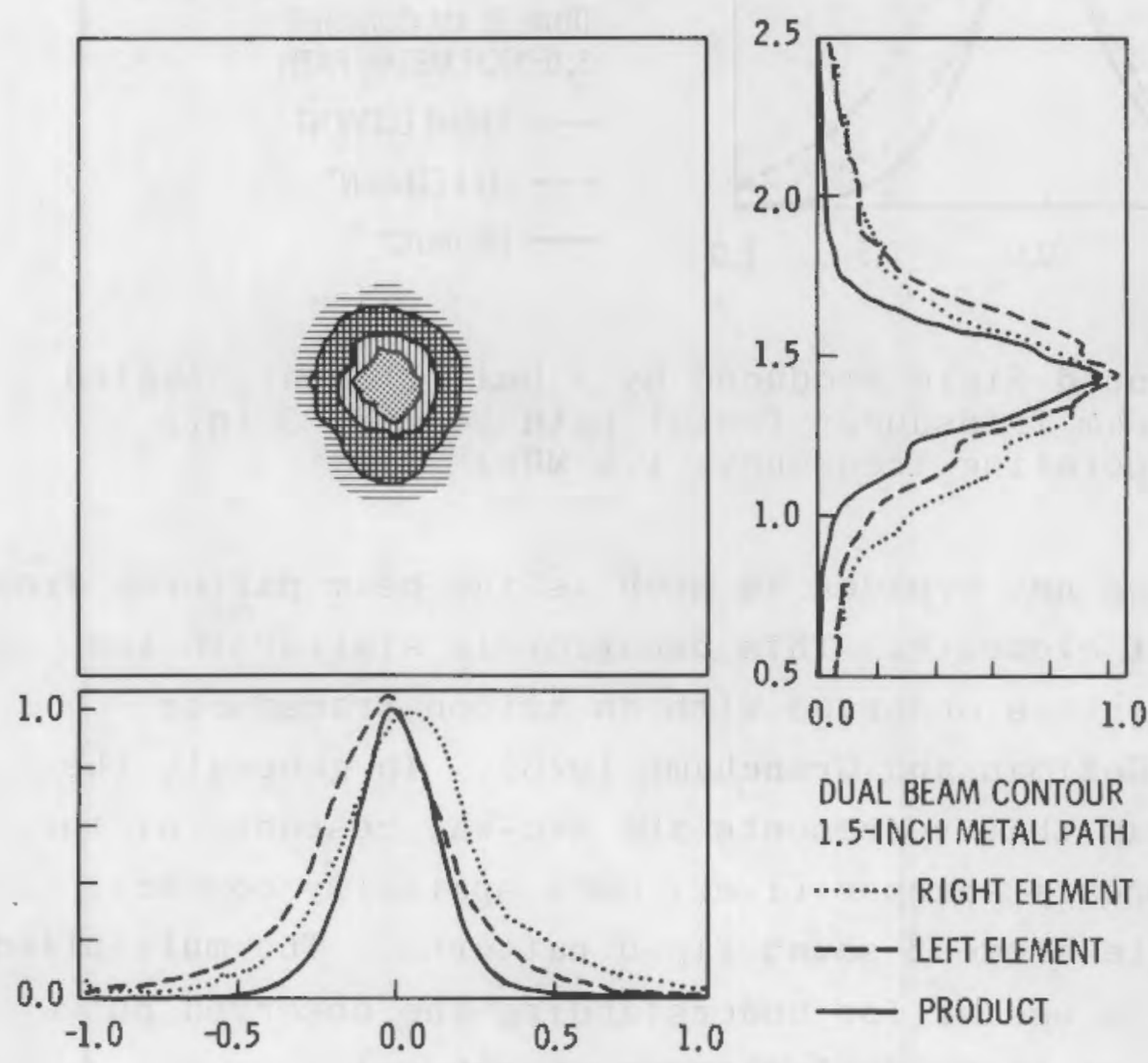

Figure 15. Sound Beam Profile Produced by a Dual-Element, Angled Beam Transducer (metal path length: 1.5 in.; operating frequency: $1.5 \mathrm{MHz}$ ) 


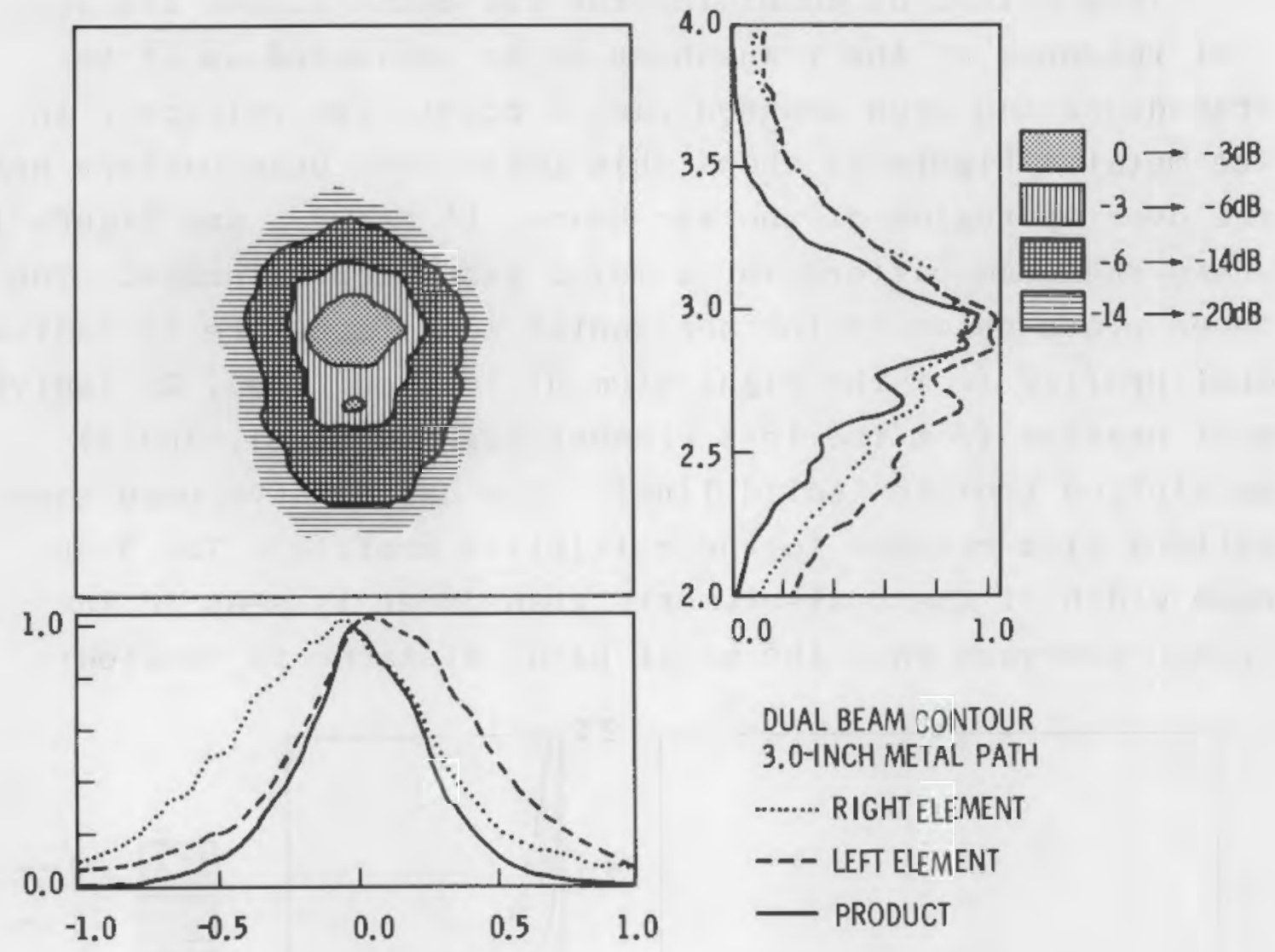

Figure 16. Sound Field Produced by a Dual-Element, Angled Beam Transducer (metal path length: 3 in.; operating frequency: $1.5 \mathrm{MHz}$ )

however it does not broaden as much as the beam patterns from the individual elements. This behavior is similar to the focusing properties observed with an axicon transducer (Burckhardt, Hoffman and Granchamp 1973). In general, the multiplied beam that represents the two-way response of the transducer appears sharper (i.e., more spatially compact) than the single element sound field patterns. The multiplied beam pattern is useful for understanding the observed pulse echo response of these dual-element search units. 


\subsection{RECEIVER-DISPLAY CHARACTERIZATION}

The receiver-display portion of an ultrasonic test instrument is the second major component characterized. The receiver is treated as a "Black Box" with an RF input port and the scope screen or chart recorder output at the output port. This approach to receiver characterization allows only total performance from a functional point of view to be evaluated. If a problem is indicated, a more detailed evaluation would be necessary to isolate the problem to a particular signal processing stage (e.g., detector, rf filter, video amplifier, etc.) within the instrument.

The overall measured properties of the receiver-display subsystem include receiver bandwidth, linearity, noise level referred to the input, and sensitivity referred to the input. As described by the test results, these properties can vary as the RF gain, video gain, RF filtering, and video filtering of the instrument are changed.

\subsection{MEASUREMENT SYSTEM}

A semi-automated measurement system has been assembled by PNL to facilitate the characterization of ultrasonic test equipment. A block diagram of this system is shown in Figure 17 .

The output pulse from the pulser section of the instrument being tested provides the "clock" pulses for this system. The limiter circuit/pulser combination provides a pulse of fixed duration to the programmable oscillator. This pulse is used to "gate" the oscillator. A burst of RF, approximately 10 microseconds long, is the input to the receiver section of the instrument under test. The time delay between transmitter output and receiver input pulse is controlled by the computer, as is the amplitude and frequency of the oscillator. By simultaneously varying the time delay and the 


\section{U.T. INSTRUMENT RECEIVER TEST}

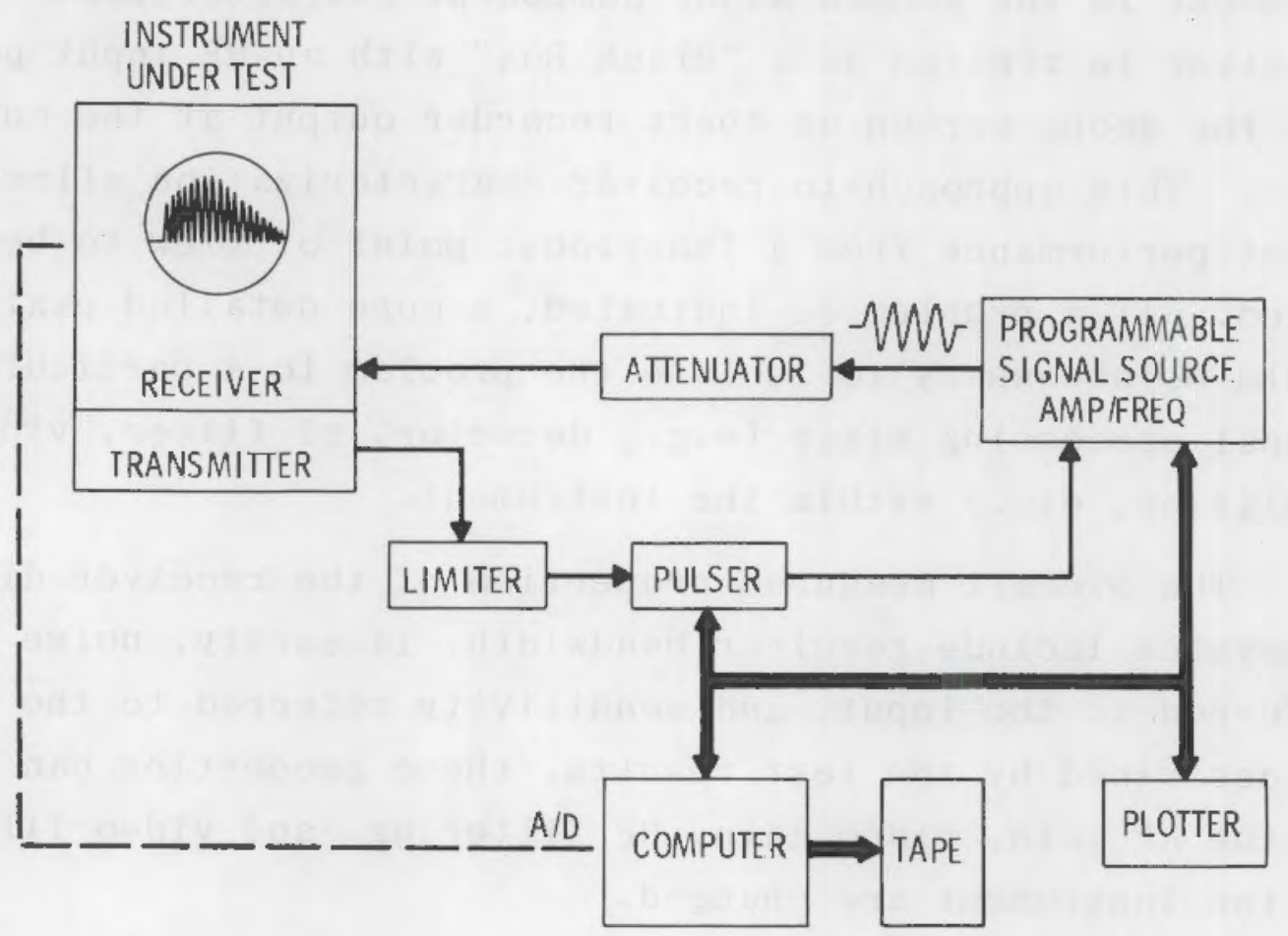

Figure 17. Block Diagram of the Electronics Used to Characterize the Performance of the Receiver-Display

oscillator frequency, a plot of the frequency response of the tested instrument is displayed on the instrument's scope screen. The linearity of the instrument can be evaluated in a similar manner.

For instruments that provide no analog signal output, the operator plays a critical role in the instrument evaluation. He is required to manually make measurements from the instrument scope screen and key them into the computer. For instruments that provide an analog output, the A/D converter can be used to totally automate the data collection process. 


\subsection{INPUT NOISE AND INPUT SENSITIVITY MEASUREMENTS}

The measurement of the input noise and sensitivity are accomplished by the operator. The input noise recorded refers to the amount of noise in microvolts RMS referred to the input when the input is terminated into 50 ohms. This measurement is generally made with the instrument at full gain. The input noise is estimated using a simple measurement technique which requires only an oscilloscope (Franlin and Hatley 1973; Gruchaila 1980). If the input noise is too high to make this measurement at full gain, the gain is reduced to a point where the noise can be measured. The quoted value of input noise is normalized as if it had been measured at full gain.

The input sensitivity of the receiver is defined as the amount of signal in microvolts RMS required at the input of the receiver, when the input is terminated into $50 \mathrm{ohms}$, to deflect the CRT trace to $50 \%$ of full scale. This measurement is either made with the instrument operating at full gain or else normalized to the full-gain condition.

\subsection{MEASUREMENT RESULTS}

In this section a series of measurements made upon the receiver-display sections of two commercially available ultrasonic test instruments are presented. The purpose of presenting these results is twofold: 1) to demonstrate how the response of a single instrument is affected by changing RF filtering and the video filtering of the instrument, and 2) to demonstrate the variation between different instruments observed when nominally similar setup procedures have been followed. Results are presented in terms of instrument frequency response and linearity. The results are intentionally presented in a manner that preserves the anonymity of the instrument manufacturer. 


\subsubsection{Frequency Response Measurements}

In Figure 18, the frequency response as measured from a commercially available instrument, Model 1, are shown. The observed output (screen deflection) is plotted as a function of the frequency of the input tone burst for a fixed input amplitude. The three curves plotted in Figure 18 refer to three different positions of the RF filter setting of the instrument; $1.0,2.25$, and $5.0 \mathrm{MHz}$. The RF filter setting appears to have two effects upon the instrument performance: 1) the setting determines the frequency of the peak of receiver response and 2 ) the setting changes the overall sensitivity of the instrument. In Figure 19, the performance of Model 1 for different filter settings $(5.0,10.0$, and wide band) is shown over a somewhat broader ( 0 to $20 \mathrm{MHz}$ ) frequency range. Examination of Figures 18 and 19 indicate a good correlation between the peak frequency of operation and the indicated filter position for all settings except wideband. The wideband position exhibits a peak response at approximately $2 \mathrm{MHz}$. The $10 \mathrm{MHz}$ filter position appears to provide a broader frequency response than the wideband position. It should also be noted that for Model 1 , the instrument sensitivity is strongly affected by the RF filter position. Several instruments of this model were evaluated. The results obtained are consistent on a unit to unit basis.

Figure 20 shows the results obtained from measurements made upon a second commercially available ultrasonic test instrument, Model 2. Measurements were made with the RF filter of the instrument set at $1.0,2.0$, and $5.0 \mathrm{MHz}$. The sensitivity of Model 2 does not appear to be strongly affected by RF filter position. The frequency of maximum response, however, does not appear to be well correlated with RF filter position. Figure 21 shows the response of Model 2 over a broader frequency range at two different RF filter positions; 

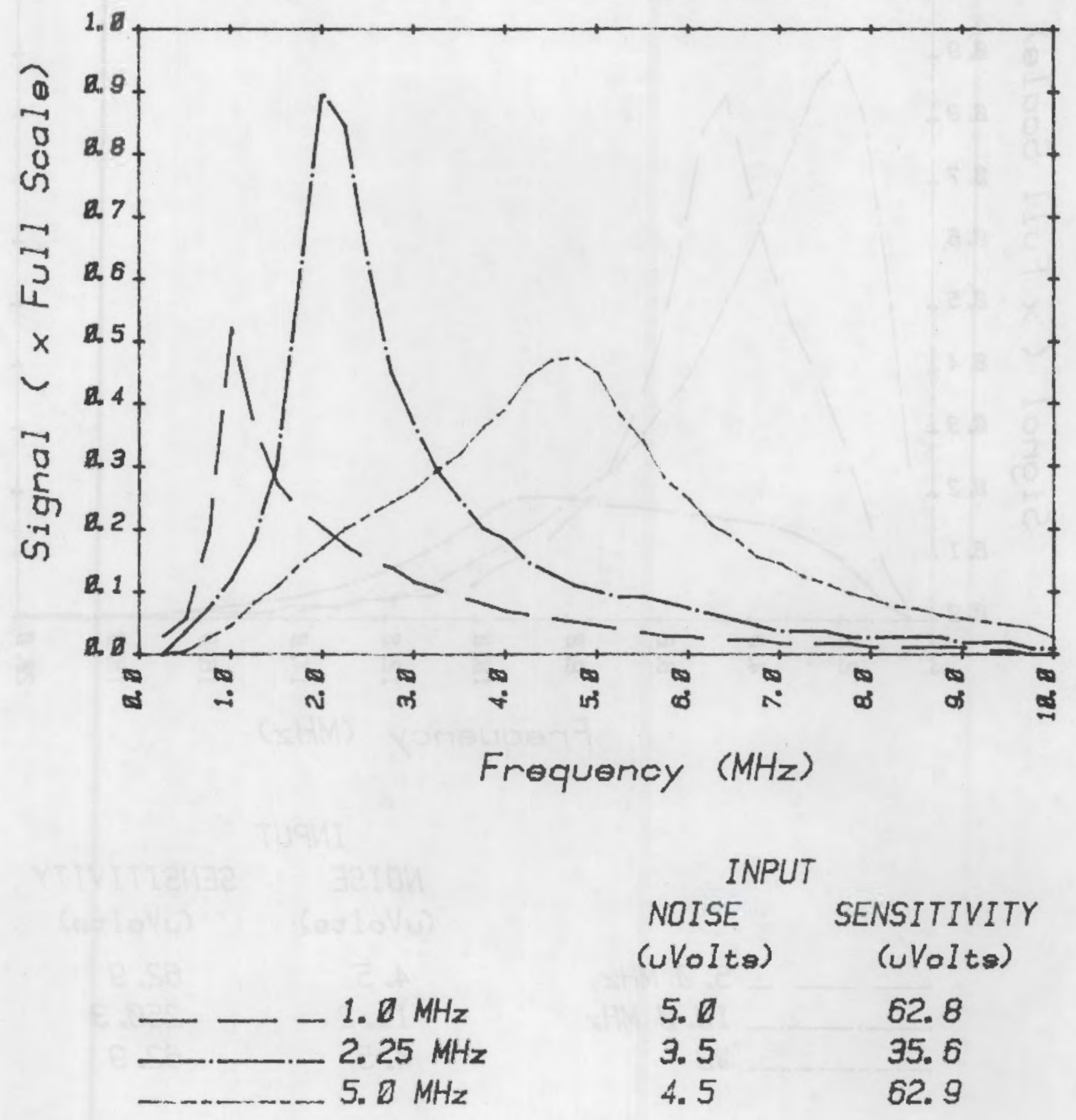

Figure 18. Frequency Response of the Receiver-Display Portion of a Commercially Available UT Instrument (Model 1) 

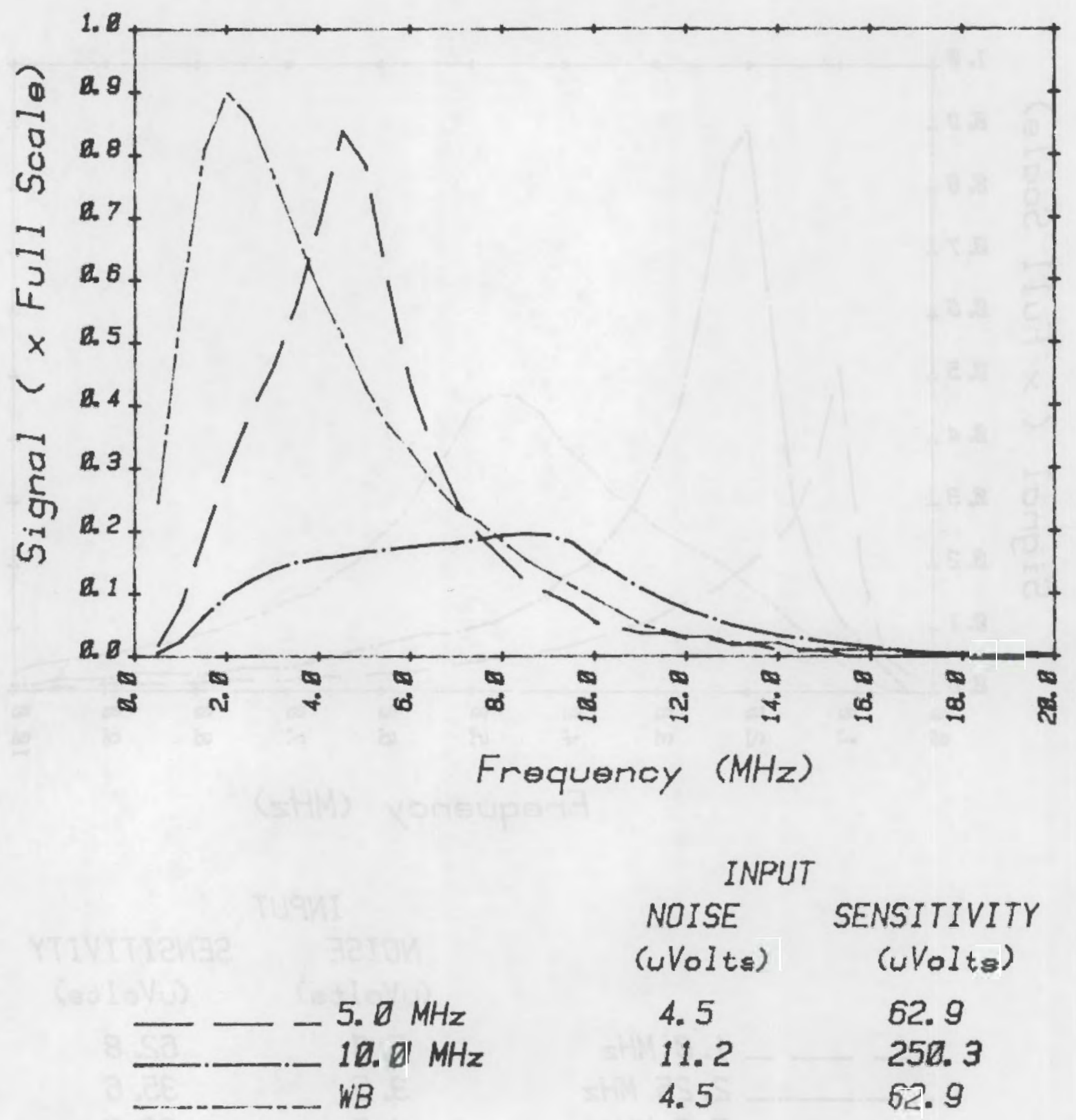

Figure 19. Frequency Response of Model 1 over a Broader Range of Frequencies 

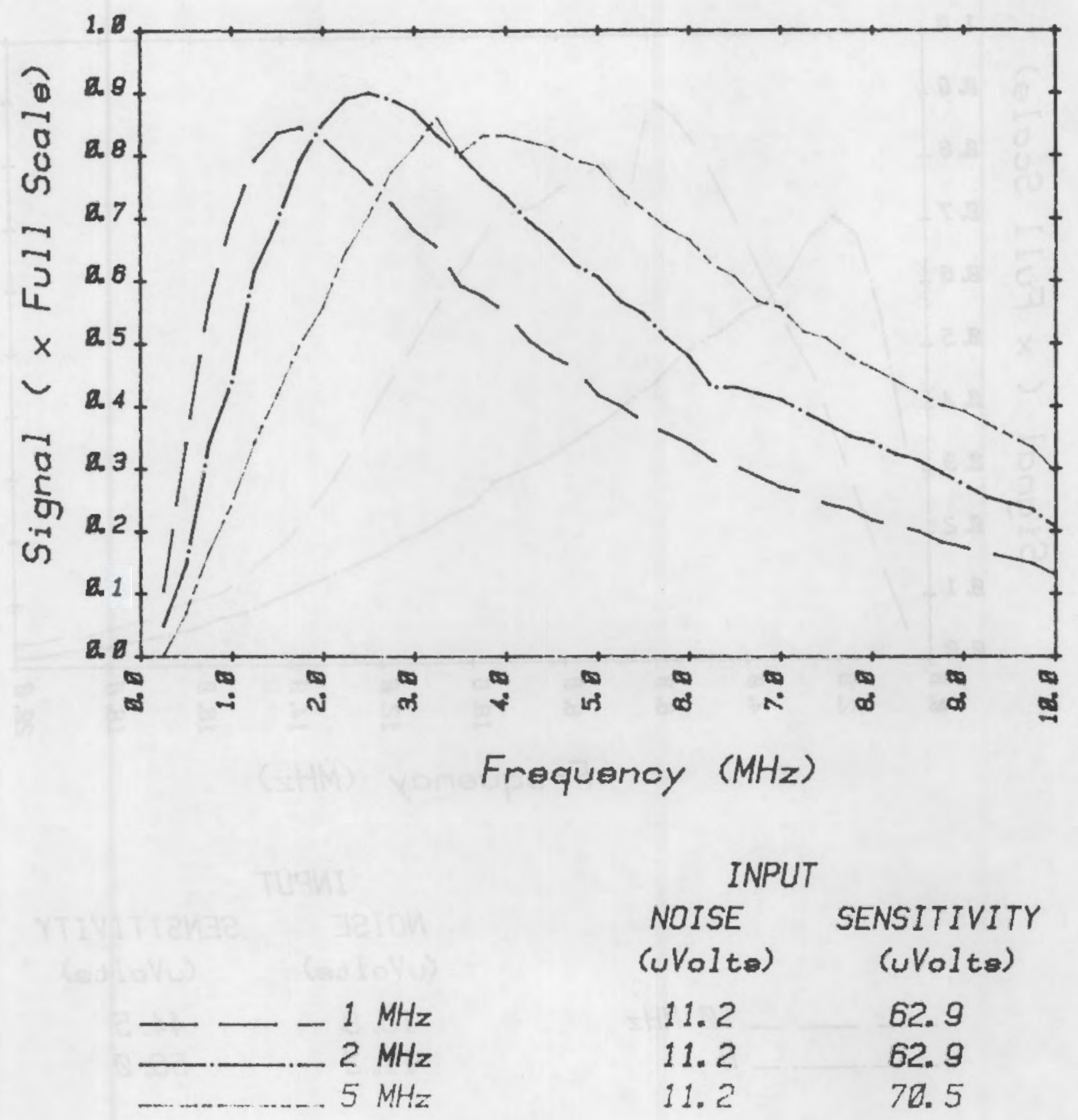

Figure 20. Frequency Response of a Second Commercially Available UT Instrument (Mode1 2) 

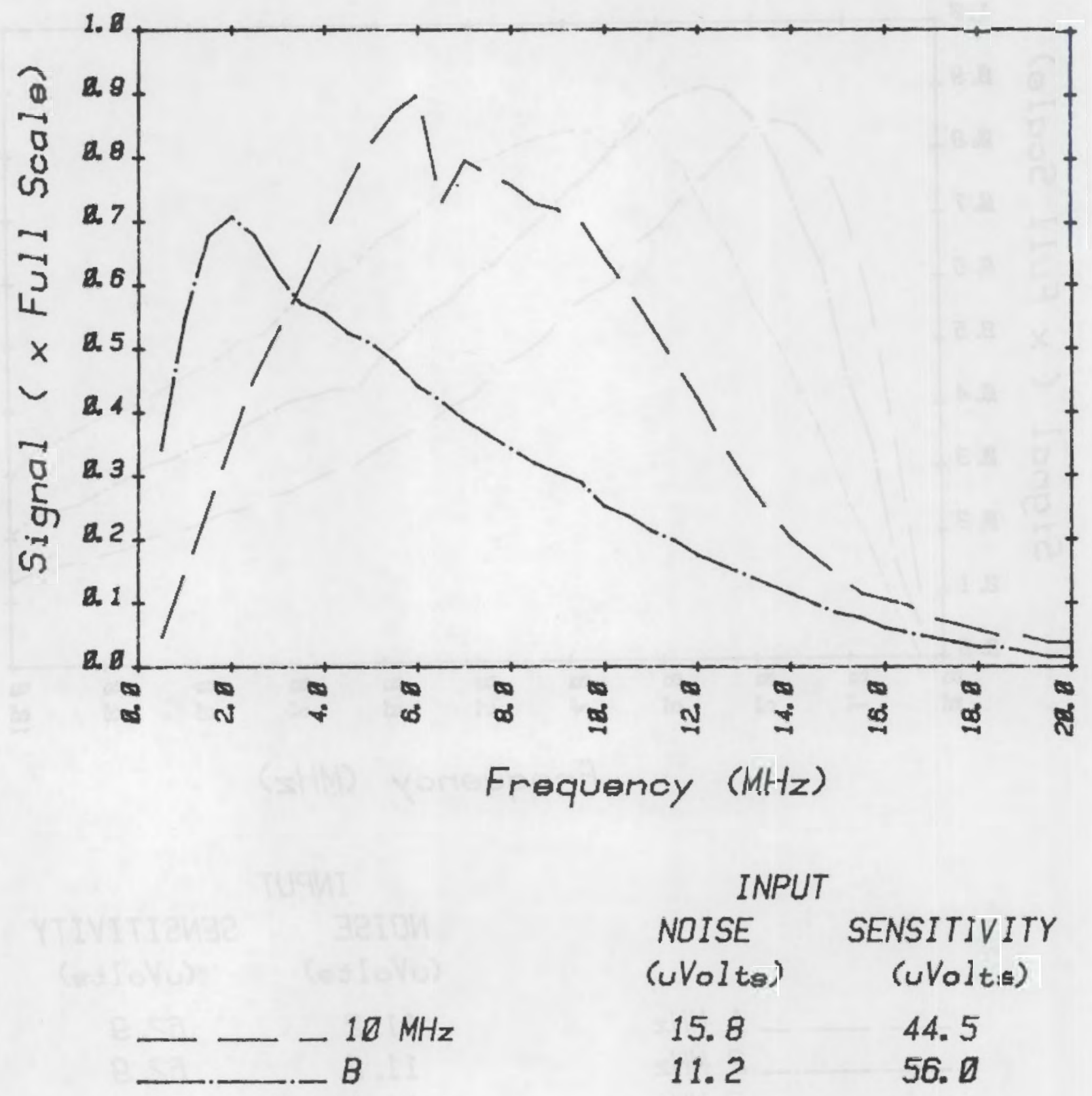

Figure 21. Frequency Response of Model 2 over a Broader Range 
$10 \mathrm{MHz}$ and broadband. The discontinuity in the response of Model 2 on the $10-\mathrm{MHz}$ filter position is noticeable and is a reproducible feature of this instrument's performance. As noted with Model 1 , the $10-\mathrm{MHz}$ filter position of Model 2 appears to provide a broader frequency response than the broadband position. Again several instruments of this model were evaluated to insure the test results were not unique to a single instrument.

\subsubsection{Linearity Measurements}

Figure 22 presents the 1 inearity as measured from Model 1. The observed output is plotted as a function of RF input amplitude for a fixed tone burst center frequency of 2.25 $\mathrm{MHz}$. The three curves plotted in Figure 22 refer to three different positions of the video filter in the receiver of the instrument. The receiver is linear for two of the three video filter positions, however, the third filter position produces a limited or compressed output. Similar results for Model 2 are presented in Figure 23. Measurements for Model 2 were made at $2.0 \mathrm{MHz}$. The output amplitude of Model 2 is seen to be linearly related to the input amplitude for all video filter positions tested. The system gain (slope of curve) appears to be affected somewhat by the video filter position. 

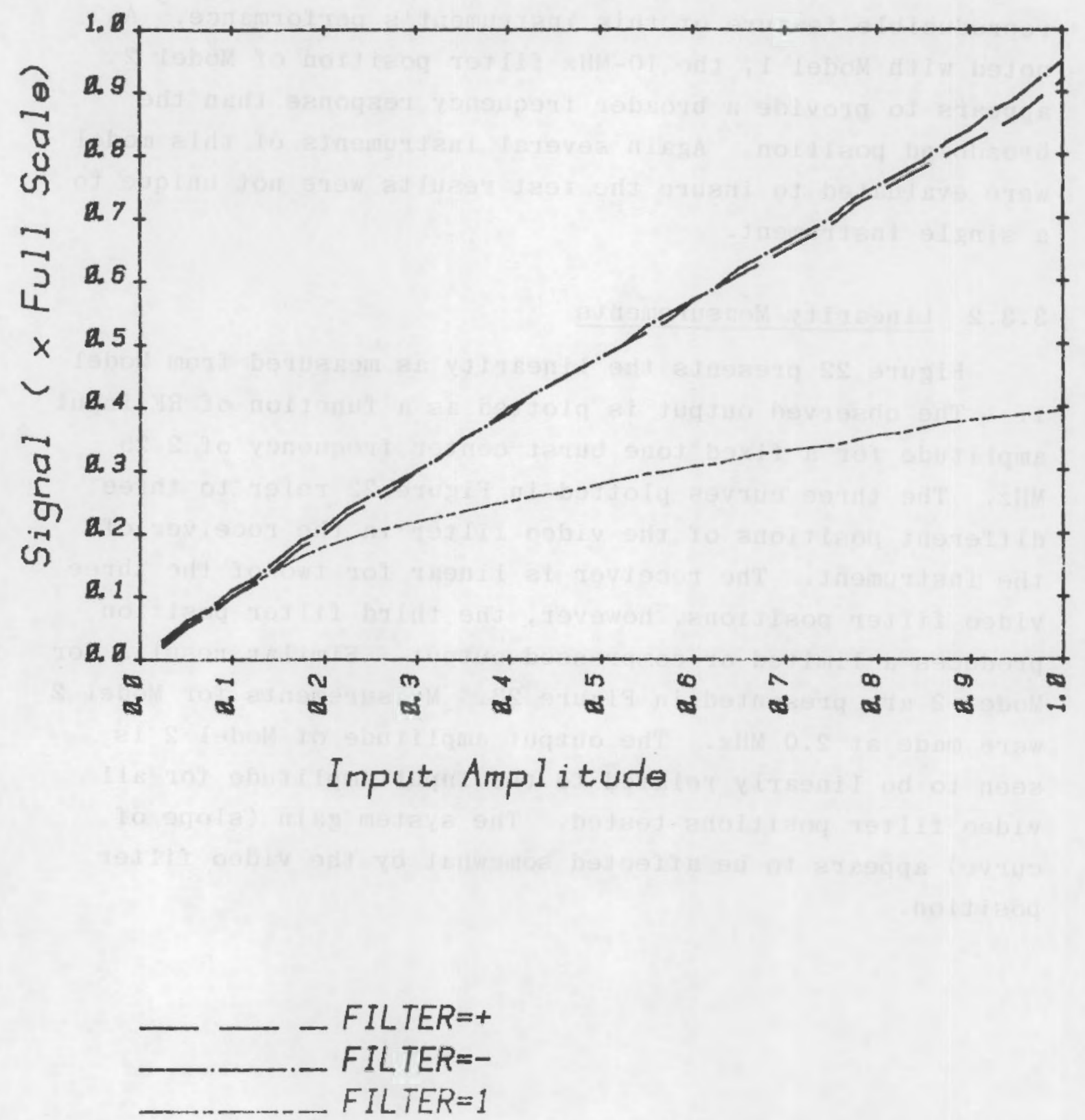

Figure 22. Results of Linearity Test Upon Model 1 

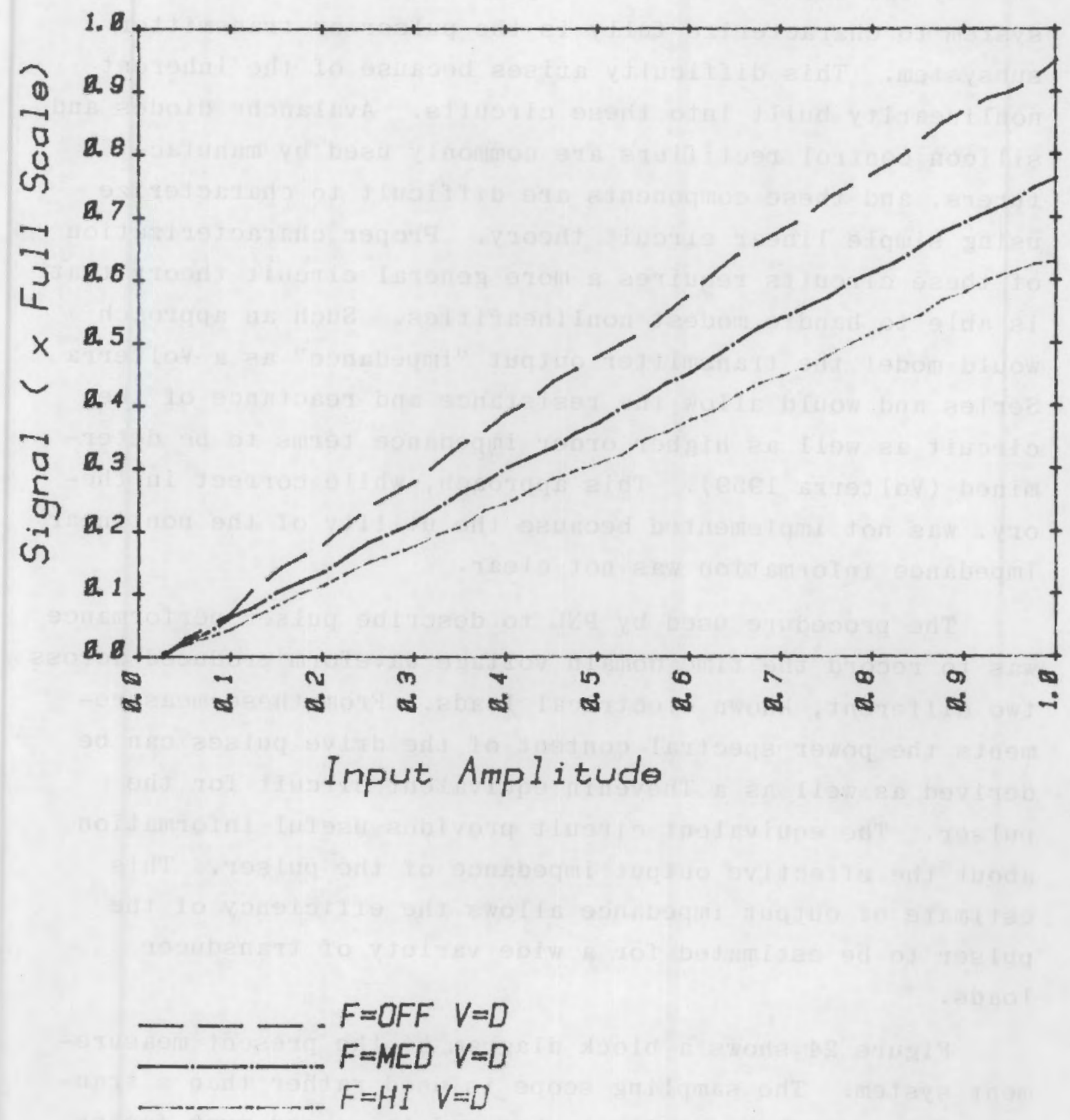

Figure 23. Results of Linearity Test Upon Mode1 2 


\subsection{PULSER CHARACTERIZATION}

By far the most difficult portion of the ultrasonic test system to characterize fully is the pulser or transmitter subsystem. This difficulty arises because of the inherent nonlinearity built into these circuits. Avalanche diodes and silicon control rectifiers are commonly used by manufacturers, and these components are difficult to characterize using simple linear circuit theory. Proper characterization of these circuits requires a more general circuit theory that is able to handle modest nonlinearities. Such an approach would model the transmitter output "impedance" as a Volterra Series and would allow the resistance and reactance of the circuit as well as higher order impedance terms to be determined (Volterra 1959). This approach, while correct in theory, was not implemented because the utility of the nonlinear impedance information was not clear.

The procedure used by PNL to describe pulser performance was to record the time domain voltage waveform produced across two different, known electrical loads. From these measurements the power spectral content of the drive pulses can be derived as well as a Thevenin equivalent circuit for the pulser. The equivalent circuit provides useful information about the effective output impedance of the pulser. This estimate of output impedance allows the efficiency of the pulser to be estimated for a wide variety of transducer loads.

Figure 24 shows a block diagram of the present measurement system. The sampling scope is used rather than a transient recorder because it can be used to record much faster events. The two electrical loads are $50 \mathrm{ohms}$ (from a standard terminator) and $500 \mathrm{ohms}$ (the input impedance of the high-voltage probe). Typical time domain signals are shown in Figure 25A. The power spectra of the transmitted pulse 


\section{U. T. INSTRUMENT - TRANSMITTER TEST}

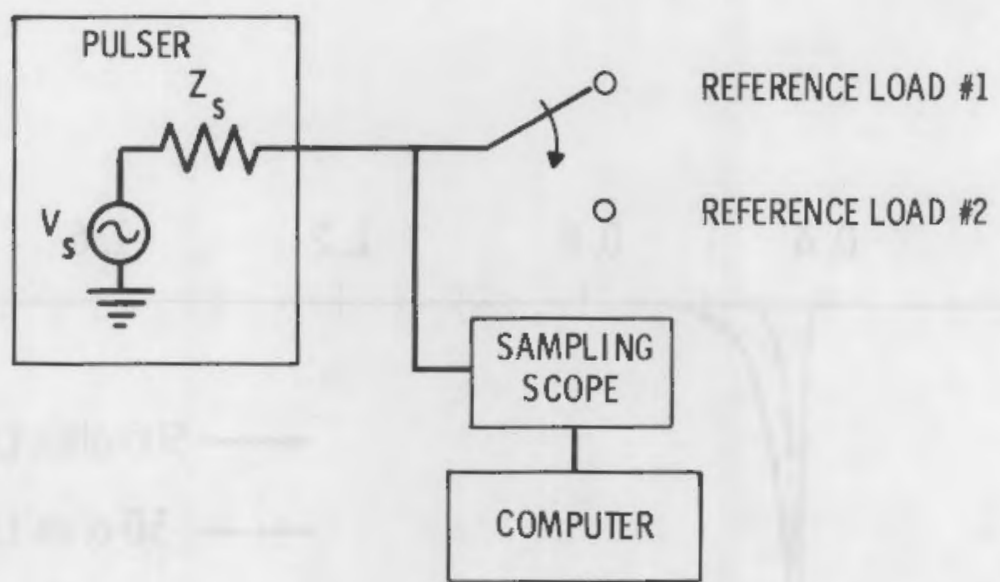

Figure 24. Block Diagram of the System Used to Characterize the Transmitter of Pulser

into these two reference loads is shown in Figure 25B. In these plots the $0 \mathrm{~dB}$ refers to a 100-volt continuous wave input. In other words, the electrical energy delivered by the 300-volt transient electrical pulse into 50 ohms at $5 \mathrm{MHz}$ is equivalent to the energy delivered by a $5-\mathrm{MHz}$ oscillator running continuously at an amplitude of approximately 15 volts ( $-16 \mathrm{~dB}$ relative to 100 volts). From the observed power spectra, as the electrical load which the pulser is required to drive is decreased the high-frequency content of the electrical drive pulse is not diminished as much as the low-frequency content of the pulse. Both of the curves in Figure 25 were taken with the internal damping control at its minimum setting.

Figure 26 shows the effect of using a maximum value of the internal damping adjustment (some instruments refer to this setting as the minimum pulse length). In this case, the 


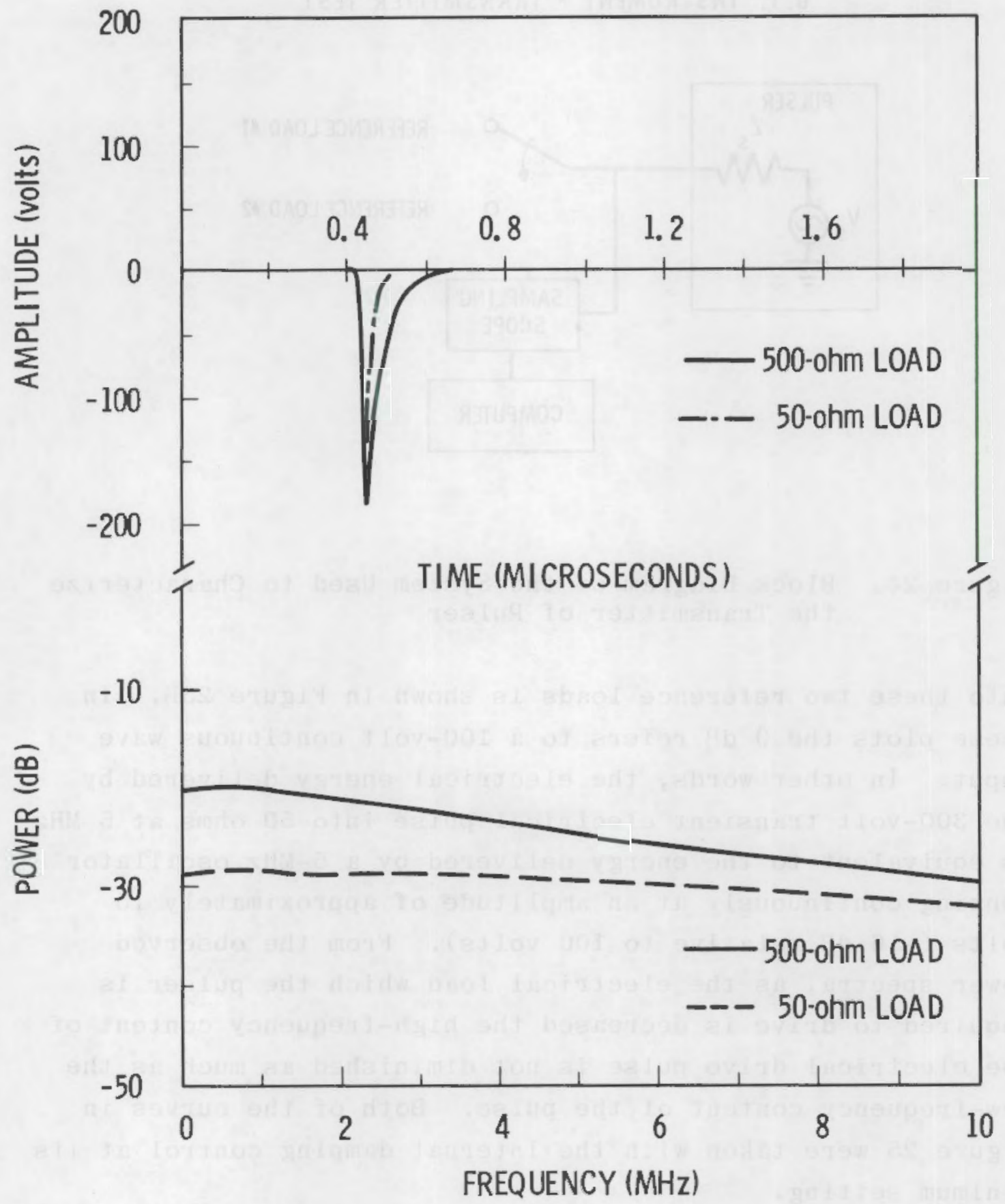

Figure 25. Results of Measurements Made Upon the Pulser Subsystem of Model 1 


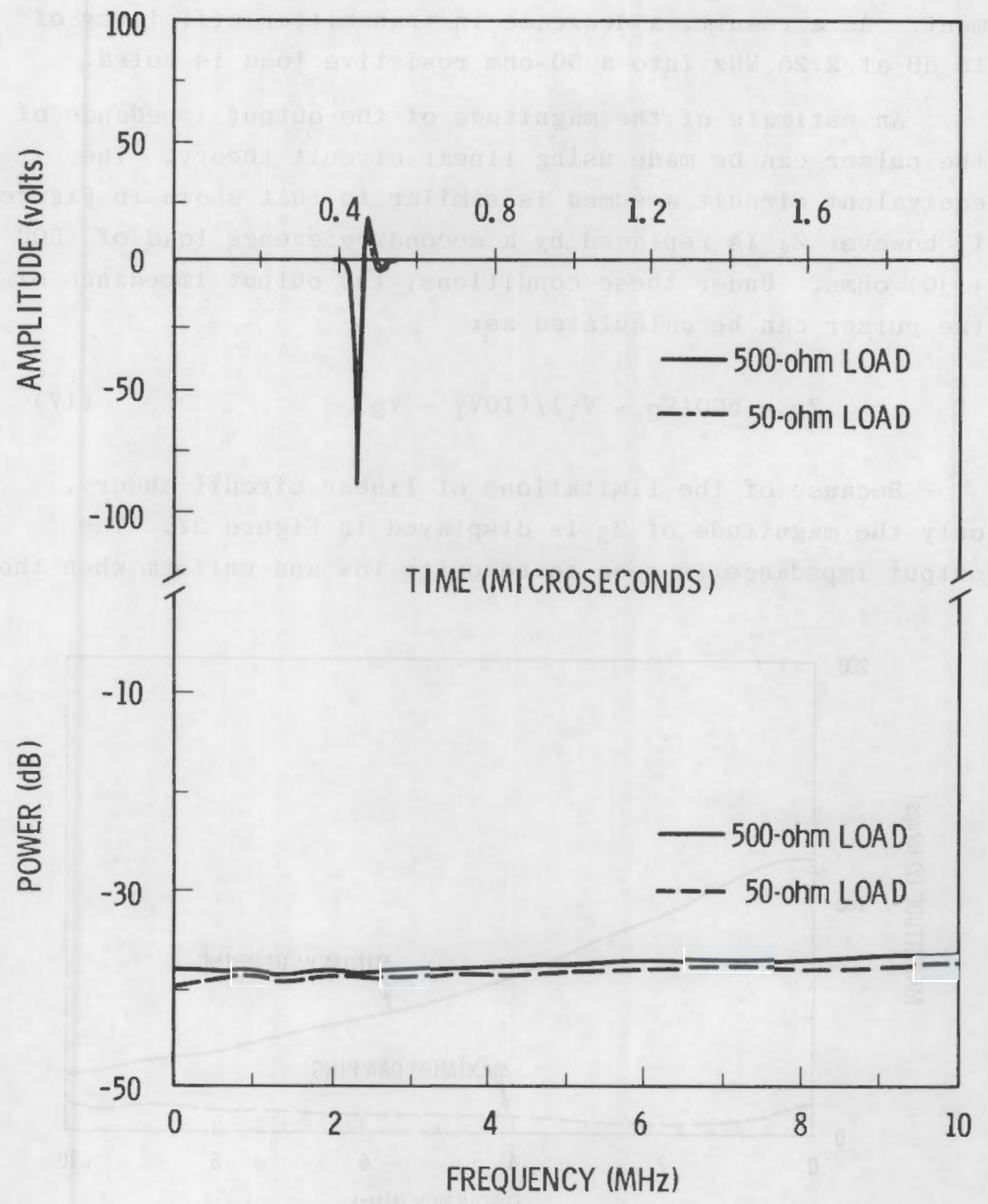

Figure 26. Measurements Made Upon Pulser Subsystem of Model 1 with Maximum Damping 
effect of the external load is minimal. Most of the electrical pulse has been "shorted out" internally in the instrument. As a result, a decrease in transmitter efficiency of $15 \mathrm{~dB}$ at $2.25 \mathrm{MHz}$ into a 50 -ohm resistive load is noted.

An estimate of the magnitude of the output impedance of the pulser can be made using linear circuit theory. The equivalent circuit assumed is similar to that shown in Figure 1 ; however $\tilde{Z}_{\ell}$ is replaced by a second reference load of (500 + j0) ohms. Under these conditions, the output impedance of the pulser can be calculated as:

$$
z_{S}=500\left(v_{2}-v_{1}\right) /\left(10 v_{1}-v_{2}\right)
$$

Because of the limitations of linear circuit theory, only the magnitude of $Z_{S}$ is displayed in Figure 27 . The output impedance is seen to be quite low and uniform when the

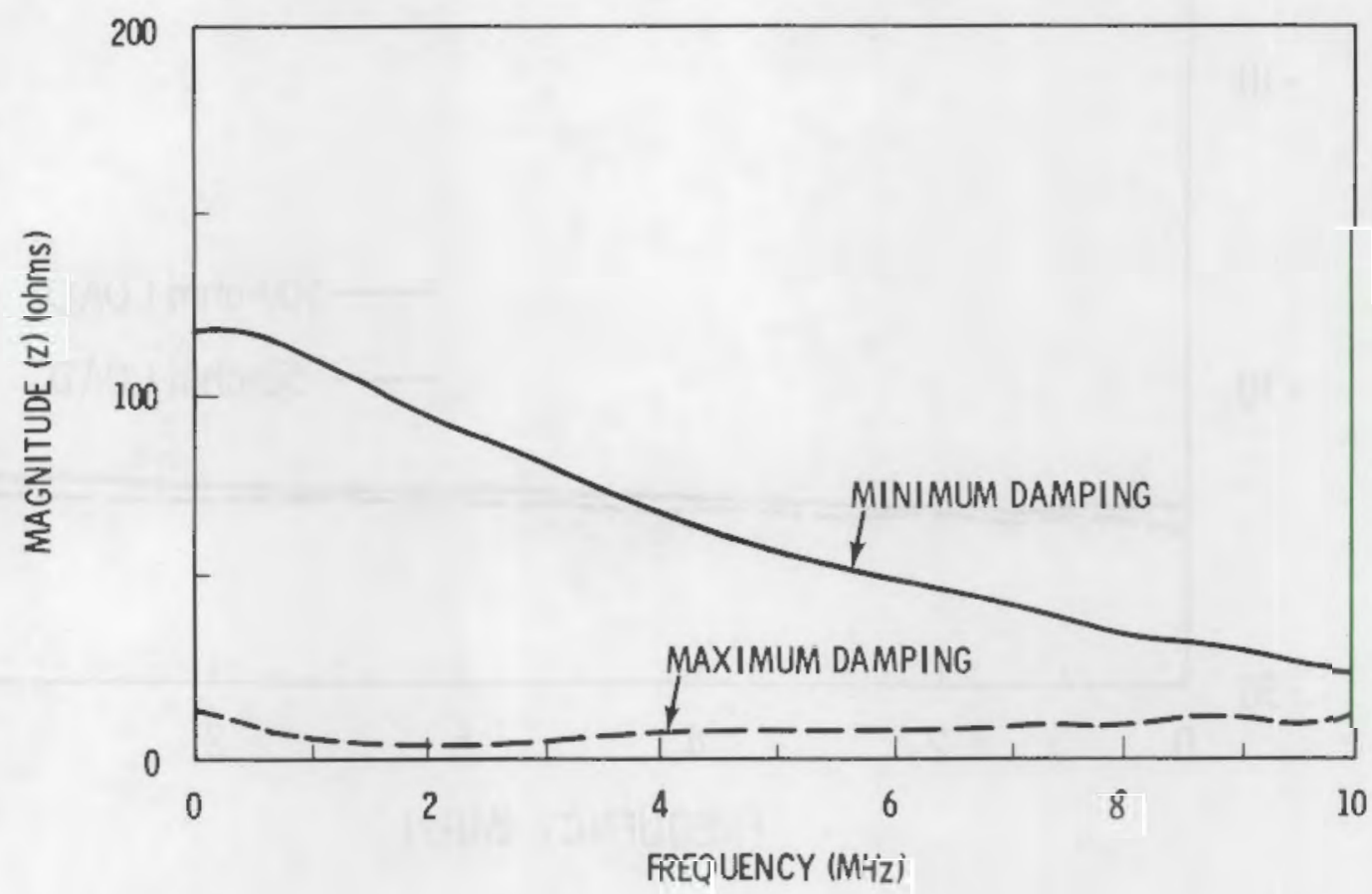

Figure 27. Calculated Output (Source) Impedance of the Pulser Subsystem of Model 1 for Two Different Damping Settings 
instrument is used with a maximum value of the internal damping adjustment. With minimum damping, the output impedance rises sharply at lower frequencies, indicating the capacitive nature of this pulser circuit.

This type of analysis (based upon linear circuit theory) although not entirely proper, has been found to be of value for estimating output impedance and for making comparison of different pulser units. 


\subsection{DISCUSSION}

A series of measurement techniques have been presented which are being used to quantify the overall performance characteristics of ultrasonic test instruments. The instrument was considered as three subsystems--a transducer or search unit, a receiver-display, and a pulser. The methods presented were chosen because they provide information about instrument performance. In addition, these methods lend themselves to automated or computerized data gathering and analysis techniques. Simplified evaluation techniques for use in the field are under investigation and will be reported on at a later date. Measurements upon a number of commercially available instruments were reported, and in the following sections a discussion of the measurement methods is presented. The minimum amount of information needed to evalnate instrument performance is also discussed.

\subsection{ULTRASONIC TRANSDUCER/SEARCH UNIT}

The ultrasonic transdncer or search unit is the most variable component of the ultrasonic test instrument. This variability results from the many different transducer designs, construction techniques, and materials used in transducer fabrication. The transducer is also susceptible to mechanical damage, wear, and deterioration due to aging. For this reason, search units should be evaluated and characterized as completely as is practical. This characterization should include an estimate of transducer 1) bandwidth or frequency response, 2) insertion loss or loop sensitivity, 3) a measure of the time domain response of the devices, 4) electrical impedance, and 5 ) sound field profiles.

Some measurement of efficiency is necessary for transducer evaluation. Either insertion loss or relative pulse echo sensitivity are adequate for this purpose. A loss of 
efficiency is the clearest indication of transducer change or malfunction. The shape of an efficiency versus frequency plot is also helpful for determining if the faulty transducer has an electrical or a mechanical defect.

The time domain or impulse response of the transducer should be measured under well controlled and reproducible conditions. Single-cycle excitation from a 50-ohm signal generator or a transient pulse from a square wave pulser are well suited to this purpose. The use of a high-voltage pulser circuit from a standard ultrasonic test instrument, even though this is the pulse that will be used in an actual inspection, can lead to results which are difficult to interpret. This difficulty can be attributable to the variable and unknown properties of the pulser circuit.

Measurement of the transducer impedance is a relatively fast means for quickly screening transducers. This measurement can be accomplished using the transient methods described in this document or by using conventional RF impedance bridges. Ideally, the impedance of a transducer should be resistive over the frequency range of operation. Evaluation of transducer impedance is valuable because it can have a marked influence on the pulser and receiver performance. For example, it is difficult to drive a transducer if its impedance is substantially lower than the output impedance of the pulser.

The mapping of sound-field profiles for a transducer provides the definitive verification of the performance of an ultrasonic transducer. Such an evaluation allows beam shapes, focal properties, sidelobe levels, etc. to be measured directly rather than inferred. 


\subsection{RECEIVER-DISPLAY CHARACTERIZATION}

The receiver frequency response and 1 inearity for a limited number of instrument settings are presently being determined. The input sensitivity and noise are also recorded. All of these measurements are made with the instrument in the transmit/receive (pitch/catch) mode of operation. These measurements are all considered essential for receiver performance evaluation. Measurement of receiver-display 1 inearity for a variety of instrument filter settings has revealed a number of receiver nonlinearities. It has also been noted that the chart recorder output of the receiver section does not identically track the video display of the echo amplitude. This condition is especially true for lowamplitude signals where it seems to be the source of instrument nonlinearity.

Other useful measurements have been identified but not yet implemented in this system. These measurements include: 1) frequency response and linearity in the pulse-echo mode, 2) input impedance, 3 ) dead time after transmit pulse saturation, and 4) dead time after echo saturation.

A good receiver-display section should have a center frequency which is well correlated with front panel settings. The bandpass should be sufficient to incorporate the frequency of the transducer. The instrument should be linear and its sensitivity should not be strongly affected by filter settings. Some degree of overlap in the bandpass for these different filter settings would allow the use of transducers with "nonstandard" operating frequencies.

\subsection{PULSER}

For characterization of the high-voltage pulser section of an ultrasonic instrument, it is necessary to measure either the time domain or frequency domain characteristics of 
the output pulse. These measurements should be carried out with the pulser working into at least two known electrical loads. By comparing the response of the pulser working into two different loads, some insight is gained into the "effective" output impedance of the pulser circuit. This insight can be gained from either a time domain or a frequency domain measurement. Standard, linear circuit theory is inadequate for fully analyzing the output impedance of the high-voltage pulser because of the many nonlinear elements in the pulser circuit.

For maximum ultrasonic output from the transducer the "ideal" pulser circuit should have as low an output impedance as is practical. In addition, controls which influence the drive characteristics, such as pulse length, damping, and amplitude, should be designed to be recorded so that measurements can be reproduced at a later time. 


\section{REFERENCES}

ASA (American Standards Association. 1970. American Standards C83.17 (also IEEE Stand. No. 177), American Standards Association, New York.

Burckhardt, C. B., H. Hoffman and P. A. Granchamp. 1973. "Ultrasound Axicon: A Device for Focusing Over a Large Depth." J. Acous. Soc. Am. 54:1628.

Carstensen, E. L. 1947. "Self-Reciprocity Calibration of Electroacoustic Transducers." J. Acous. Soc. Am. 19:961.

Erikson, K. R. 1974. "Tone-Burst Testin of Pulse-Echo Transducers." IEEE Trans. Sonics and Ultrasonics. SU-26:7.

Foldy, L. L. and H. Primakoff. 1947. "A General Theory of Passive Linear Electroacoustic Transducers and the Electroacoustic Reprocity Theorem. I." J. Acous. Soc. Am. 17:109.

Franlin, G. and T. Hatley. 1973. "Don't Eyeball Noise." Electronics Design. 24:184.

Gruchalla, M. E. 1980. "Measure Wide-Band White Noise Using a Standard Oscilloscope." Electronic Design News, 157.

MacLean, W. R. 1940. "Absolute Measurement of Sound Without a Primary Standard." J. Acous. Soc. Am. 12:140.

O'Donnel1, M., L. J. Busse and J. G. Miller. 1981. "Piezoelectric Transducers." In Methods of Experimental Physics, P. D. Edmund, ed., Vol. 19, pp. 29-65, Academic Press. New York, New York.

Papadakis, E. P. 1977. "Ultrasonic Transducer Evaluation in Five 'Domains': Time, Space, Frequency, Surface Motion, and Theory." Ultrasonics Symposium Proceedings, Cat. \#77 CH1264-1 SU, IEEE.

Posakony, G. J. 1975. "Engineering Aspects of Ultrasonic Piezoelectric Transducer Design." Ultrasonics Symposium Proceedings, Cat. \#75 CHO 994-4SU, IEEE.

Primakoff, H. and L. L. Foldy. 1947. "A General Theory of Passive Linear Electroacoustic Transducers and the Electroacoustic Reciprocity Theorem. II." J.Acous. Soc. Am. 19:50.

Reid, J. M. 1974. "Self-Reciprocity Calibration of EchoRanging Transducers." J. Acous. Soc. Am. 55:862. 
Sabin, G. A. 1964. "Calibration of Piston Transducers at Marginal Test Distances." J.Acous. Soc. Am. 36:168.

Sachse, W. "On the Reversibility of Piezoelectric Transducers." MSC Report 2926, Cornell University, I thaca, New York.

Sachse, W. and N. N. Hsu. 1979. "Ultrasonic Transducer for Materials Testing and Their Characterization." In Physical Acoustics, XIV. W. P. Mason and R. N. Thurston, eds., Academic Press, New York, New York.

Sittig, E. K. 1967. "Transmission Parameters of ThicknessDriven Piezoelectric Transducers Arranged in Multilayer Configuration," IEEE Trans. Sonics and Ultrasonics, SU-14:167.

Volterra, V. 1959. Theory of Functionals and of Integral and Integro-Differential Equations. Dover, New York, New York.

Weiner, D. D. and J. E. Spina. 1980. Sinusoidal Analysis and Modeling of Weakly Nonlinear Circuits. Van Nostand, New York, New York.

Wuestenberg, H. 1970. "Contactless Electrodynamic Ultrasonic Transducers and Their Application in Ultrasonic Inspection." B-4. In Proceedings of the Sixth International Conference on NDT, Hanover, Germany.

Wuestenberg, H., E. Mundry, W. Moehrle and W. Wegner. 1979. "Experiences with the Use of Electrodynamic Microprobes for Probe Characterization." $4 \mathrm{H}-6$. In Proceedings of the Ninth World Conference on NDT. 

NUREG/CR-2264

PNL -4215

\section{DISTRIBUTION}

No. of

Copies

OFFSITE

\section{U.S. Nuclear Regulatory Commission \\ Division of Reactor Safety Research \\ 7920 Norfolk Avenue \\ Bethesda, MD 20014}

400 U.S. Nuclear Regulatory Commission

Division of Technical Inf ormation and Document Control

7920 Norfolk Avenue

Bethesda, MD 20014

M. R. Hum

U.S. Nuclear Regulatory Commission

Materials Engineering Branch

Mail Stop 318

Washington, DC 20555

Stewart D. Ebneter

USG Nuclear Regulatory

Commission

1075 Brentwood Dr.

Pottstown, PA 19464

2 DOE Technical Information Center

Robert R. Arant

125 Seriff Dr.

Lima, OH 45807

Larry J. Chockie 6729 Landerwood Lane

San Jose, Calif 95120
No. of

Copies

70 Ralph G. Crawford

270 Inglewood $\mathrm{Dr}$.

Pittsburgh, PA 15228

David E. Dier

73 Wildwood Dr.

Barrington, IL 60010

Solomon Goldspiel

732 Gerald Court

BrookTyn, NY 11235

Joseph D. Marble

69 Hande 1 Lane

Cincinnati, $\mathrm{OH} 45218$

Warren H. Mayo

40 Newgate Road

Pittsburgh, PA 15202

Henry D. Monsch

1652 South Abrego Dr.

Green Valley, AZ 85614

Bernard 0strofsky

P.0. Box C

Naperville, IL 60566

Harold L. Pinsch

4117 Phinney Bay Dr.

Bremerton, WA 98310 
No. of

Copies

Robert J. Roehrs 4762 Barroyal Dr. St. Louis, MO 63128

Walter N. Roy 302 Potter Road

Framingham, MA 01701

John G. Rumbold

1014 Whitehead Road Ext.

Trenton, NJ 08638

F. J. Sattler

873 old Spring Road

Copley, OH 44321

Alan Schoffman

592 Warwick Avenue

Teaneck, NJ 07666

Michael L. Stellabotte

384 Westfield $\mathrm{Dr}$.

Broomall, PA 19008

William A. Sverkric

5200 Arrowood Ct.

Columbus, $\mathrm{OH} 43229$

Carlos F. Morcate

ACF Industries

W K M Valve Div.

Box 2117

Houston, TX 77001

Don L. Conn

ARMCO Inc.

Research Center

Middletown, $\mathrm{OH} 45043$

Paul T. Duffey

Al Tech Specialty Steel Corp.

Spring St. Road

Watervliet, NY 12189

Thomas F. Drumwright, Jr. Alcoa Technical Center Alcoa Center, PA 15069
No. of

Copies

Jack B. Morgan

Allegheny Ludlum Industries Inc.

Research Center

Brackenridge, PA 15014

John Winslow Newman

Allied Piping Prod. Co.

2550 Blvd. of the Generals

Norristown, PA 19403

Moss V. Davis, Dr.

American Welding Soc., Inc.

Box 351040-550 NW Le Jeune

Miami, FL 33135

Carl Russell

Aquatic Professionals, Inc.

5151 Michelldale A-5

Houston, TX 77092

Arnold H. Greene

Arnold Greene Testing

Labs, Inc.

6 Huron Drive

Natick, MA 01760

Howard E. Van Valkenbu

Automation Industries, Inc.

P. 0. Box 3500

Danbury, CT 06810

H. C. Graber

Babcock \& Wilcox

91 Sterling Avenue

$\mathrm{M} / \mathrm{S}$ BW041B

Barberton, OH 44203

Harold C. Graber

Babcock \& Wilcox

4-1-48

91 Stirling Ave.

Barberton, $\mathrm{OH} 44203$

M. G. Hacker

Babcock \& Wilcox

Nuclear Power Generation Dept.

P. 0. Box 239

Lynchburg, VA 24505 
No. of

Copies

A. Holt

Babcock \& Wilcox

91 Sterline Avenue

Barberton, OH 44203

W. E. Lawrie

Babcock \& Wilcox

P.0. Box 1260

Lynchburg, VA 24505

William E. Lawrie

Babcock \& Wilcox

Lynchburg Research Center

P.0. Box 239

Lynchburg, VA 24505

B. L. Laubert

Babcock \& Wilcox

Tubular Products Division

640 E. Keystone St.

Alliance, $\mathrm{OH} 44601$

Maryellen Robards

Bardel, Inc.

13810 Enterprise Ave.

Cleveland, $\mathrm{OH} \quad 44135$

G. Joseph Wolf

Bethlehem Steel Corp.

Room 341 GSO

Bethlehem, PA 18016

Wayne J. Ferguson, II

Black-Civalls \& Bryson

4011 E. 67th St.

Tulsa, OK 74136

Samuel Greenberg

B1dg. 142 - Apt. 207

9861 Sunrise Lakes Blvd.

Sunrise Ft. Laude., FL 33322

Carl H. Himmelman

Borg-Warner Corp.

Byron Jackson Pump Division

5800 S. Eastern Ave.

Commerce, CA 90040
No. of

Copies

William C. Lowenkamp

Box 878 - Monticello Road

Hazlehurst, MS 39083

Paul J. Bulten

Brown \& Root Inc.

6021 Bonhomme-Crest Park

Bldg.

Houston, TX 77036

Ronald C. Bevan

CBL Industries Inc.

13810 Enterprise Avenue

Cleveland, $\mathrm{OH} 44135$

Vincent L. Gorka

Carpenter Technology Corp.

133 Springfield Road

Union, NJ 07083

Richard B. Moyer

Carpenter Technology Corp.

101 W. Bern St.

Reading, PA 19603

F. C. Berry

Chicago Bridge \& Iron

P.0. Box 277

Burmingham, AL 35201

J. L. Wood

Combustins Power $\mathrm{Co}$.

1945 Parnall Road

Jackson, MI 49201

0. F. Hedden

Combustion Engineering

Dept. $9004-2228$

1000 Prospect Hill Road

Windsor, CT 06095

E. J. Parent

Combustion Engineering

Dept. 9451-201

Windsor, CT 06095 
No. of

Copies

T. L. Bailey

Combustion Engineering Inc.

FPSM Quality Assurance

911 W. Main St

Chattanooga, TN 37401

Donald L. Crabtree

Comustion Engineering, Inc.

911 W. Main St.

Chattanooga, TN 37402

Howard B. Aaron

D A B Industries Inc.

Vice President Engrg. \& Res.

466 Stephenson Highway

Troy, MI 48084

Rudolf W. Zillmann, Dr

DCASR-Clevel and DCRO-QT.

1240 E. 9th St.

Cleveland, $\mathrm{OH} 44199$

A. A. Churm

DOE Patent Division

9800 S. Cass Avenue

Argonne, IL 60439

W. J. McGonnagle

$\mathrm{DOE} / \mathrm{NBL}$

9800 S. Cass Avenue

Argonne, IL 60439

J. F. Cook

EG\&G Idaho, Inc.

P.0. Box 1625

Idaho Falls, ID 83401

D. E. McDonald

EPRI NDE Center

P.0. Box 217097

Charlotte, NC 28221

John R. Zimmerman

East Texas State University

College of Sciences \& Tech.

East Texas Station

Commerce, TX 75428
No. of

Copies

John Waskow

Eastman Kodak Co.

Kodak Park Div. B Idg. 23

Rochester, NY 14650

Gary Dau

Electric Power Research Inst.

P.0. Box 10412

Palo Alto, CA 94303

Kirit V. Smart

Florida Power \& Light Co.

Plant Construction Dept.

400 N. Congress Ave.

P.0. Drawer D

West Palm Beach, FL 33402

Emmanue 1 P. Papadakis

Ford Motor Co.

Mfg. Dev. Center

621 Henley Dr.

Birmingham, MI 48008

Gordon R. Woodrow

G.0. Carlson Inc.

Marshalltown Road

Thorndale, PA 19372

L. J. Chockie

General Electric

$M / C 363$

175 Curtner Avenue

San Jose, CA 95125

B. R. Rajala

General Electric

175 Curtner Avenue

M/C 273

San Jose, CA 95125

Gilbert E. Joly

General Electric Co.

1 River Road, Bldg. 28-450

Schenectady, NY 12345

Derek J. Sturges

General Electric Co.

Interstate Hwy 75-B1dg. 700-E45

Cincinnat $\mathrm{i}, \mathrm{OH} \quad 45215$ 
No. of

Copies

C. D. Cowfer

General Public Utilities

100 Interpace Parkway

Parsippany, NJ 07054

V. H. Hight

Gilbert Associates

P.0. Box 1498

Reading, PA 19603

Bernard M. Strauss

Gulf Science \& Technology Co.

P.0. Drawer 2038

Pittsburgh, PA 15230

D. R. All an

Guterl Special Steel Corp.

P.0. Box 509

Ohio Street

Lockport, NY 14094

Robert Goldstein

Guterl Special Steel Corp

Ohio St.

P.0. Box 509

Lockport, NY 14094

Robert V. Harris

Harisonic Labs Inc.

7 Hyde Street

Stamf ord, CT 06902

F. T. Duba

Hartford Steam Boiler

Inspection and Insurance

Company 56 Prospect Street

Hartford, CT 06102

Dennis Allen White

Hartford Steam Boiler

Inspection and Insurance

8 Colburn Road

Stafford Springs, CT 06076

Ted Kirk

Huntington Alloys Inc.

P.0. Box 1958

Huntington, WV 25720
No. of

Copies

\author{
Daniel F. McGrath \\ Ingersoll-Rand 0il Field \\ Products Co. \\ P.0. Box 1101 \\ Pampa, TX 79065
}

Frank E. Faris

Interdevelopment, Inc.

Rutherford B. Hayes B Idg.

2361 Jeff Davis Hwy - STE 1014

Arlington, VA 22202

Jesse W. Caum

International Center for

Diffraction Data

1601 Park Lane

Swarthmore, PA 19081

Virgil B. Roberts

International Nickel

Huntington Alloys Inc.

Guyan River Road Box 1958

Huntington, WV 25720

F. L. Becker

J. A. Jones Applied Research Co.

1300 Harris Blvd.

P.0. Box 217097

Charlotte, NC 28221

R. M. Stone

J. A. Jones Applied Research Co. 1300 Harris Blvd.

P.0. Box 217097

Char lotte, NC 28221

Robert S Spinetti

Jones \& Laughlin Steel Corp.

Works Testing Lab

P.0. Box 490

Aliquippa, PA 15001

Jeffrey A. Bailey

Kaiser Aluminum \& Chemical

Box 877 - 6177 Sunol Blvd.

Pleasanton, CA 94566 
No. of

Copies

Robert B. Wilson

Kennametal Inc.

1 Lloyd Avenue

Box 231

Latrobe, PA 15650

John E. Bobbin

Krautkramer Branson

International

250 Long Beach Blvd Box 408

Stratford, CT 06497

Theodore G. Lambert

Lambert Mac Gill Thomas, Inc.

771 E. Brok aw Road

San Jose, CA 95112

George V. Aseff, Sr.

$\mathrm{L}$ aw Engineer Testing Co.

396 Plasters Ave. NE

Atlanta, GA 30324

Edward Karapetian

Los Angeles City of.

Dept. of Water \& Power-Room 1023

Box 111

Los Angeles, CA 90051

John P. Sunukjian

Lukens Steel Co.

No. 2421

Coatesville, PA 19320

E. B. Lewis

Lynchburg Foundry $\mathrm{Co}$.

NDT-Research \& Development

P.0. Drawer 411

Lynchburg, VA 24505

Robert A. Hanson

MPB Corporation

P.0. Box 547

Keene, NH 03431

Matthew J. Dashukewich

Magnaflux Corp.

230 Murphy Road

Hartford, CT 06114
No. of

Copies

Peter J. Suhr

Magnetic Analysis Corp.

$535 \mathrm{~S}$. Fourth Avenue

Mt. Vernon, NY 10550

B. Boro Djordjevic Martin Marietta Labs. 1450 S. Rolling Road Baltimore, MD 21227

Richard J. Meyer

McDonnell Douglas Corp.

Dept. 8528 - B1dg. 220

P. 0. Box 516

St. Louis, MO 63166

Mr. Connie Presley

Mid Continent Steel Casting

Div. of Kast Metals

Box 6611M

Shreveport, LA 71106

Richard S. Humphrey

Monsanto Co.

800 N. Lindbergh Blvd F4EE

St. Louis, MO 63166

Claude E. Jaycox

Municipal Testing Lab. Inc.

160 Lauman Lane

Hicksville, NY 11801

Charles H. Craig

Naval Sea Systems Command

Sea 05E2

Washington, DC 20362

Cliff ord $\mathrm{W}$. Anderson

Naval Surface Weapons Center

Code R34

White 0ak

Silver Spring, MD 20910

Giancar lo Mazzoleni

Newage Industries, Inc. 2300 Maryl and Road

Willow Grove, PA 19080 
No. of

Copies

Robert R. Hardison

Newport News Shipbuilding \& Drydock CC - Dept. 035

4100 Washington Ave. Newport News, VA 23607

E. Debarba

Northeast Utilities

P.0. Box 270

Hartford, CT 06101

P. S. Barry

Nuclear Energy Services Inc. NES Div.

Shelter Rock Road

Danburg, CT 06810

John H. Weiler

Offshore Power Systems

8000 Arlington X-Way

Jacksonville, FL 32211

Kenneth $P$. Weaver

Ohio Steel Tube Co.

West Main St.

Shelby, $\mathrm{OH} 44875$

Robert Smetana

Drbit Industries, Inc.

6840 Lake Abram Dr.

Middleburg Hts, OH 44130

Richard I. Buckley

P.0. Box 941

Attleboro, MA 02703

James D. Nordstrom

PA Incorporated

P.0. Box 7631

Houston, TX 77007

F. J. Dodd

Pacific Gas and Electric Co.

77 Beal Street, Rm 2411

San Francisco, CA 94106
No. of

Copies

Frederick H. C. Hotchkiss

Panametrics, Inc.

221 Crescent Street

Waltham, MA 02154

College of Textile Science

Pastore Philadelphia Library

3243 School Lane

Philadelphia, PA 19144

P. J. Herbert

Paul J. Herbert, Inc.

212 Paseo Del Rio

Moraga, CA 94556

Carl B. Shaw

Portland General Electric Co.

Generation Engrg. S B Bridge

121 SW Salmon St.

Portland, OR 97204

C. R. Feimley, Jr.

Executive Secretary

Pressure Vessel Research

Committee Welding Research Council

345 E. 47th Street

New York, NY 10017

Noel B. Proctor

Proctor Inspection

Consultants Inc.

1507 Brooks

Rosenberg, TX 77471

Roger P. Maickel, Dr.

Purdue University - Dept. of

Pharmacology \& Toxicology

School of Pharmacal Sci.

W. Laf aette, IN 47907

James H. Bly

Radiation Dynamics, Inc.

56 Fieldstone Drive

Syosset, NY 11791 
No. of

Copies

Neil W. Breslow

Radiatronics NDT, INC

P.0. Box 12308

Overland Park, KS 66212

J. Harvey Wynne

Republic Steel Corp.

1570 Glenhardie Road

Wayne, PA 19087

Richard Gaydos

Republic Steel Corp.

Tech Services

P.0. Box 6778

Cleveland, $\mathrm{OH} \quad 44101$

Carlton E. Burley

Reynolds Metals Co.

Box 27003

Richmond, VA 23261

Warren L. Mehnert

Sandusky Foundry \& Machine Co.

615 W. Market St.

Sandusky, OH 44870

Jerry T. McElroy

Search Unit Systems Inc.

12918 Bandera Road

San Antonio, TX 78228

Jack W. Raisch

Sonic Instruments, Inc. 1014 Whitehead Road Ext.

Trenton, NJ 08638

Roy Gromlich

Sonic Instruments Inc.

1018 Whitehead Road

Trenton, NJ 08638

W. T. Clayton

Southwest Research Inst. 6220 Culebra Road

P.0. Drawer 28510

San Antonio, TN 78284
No. of

Copies

W. T. Flach

Southwest Research Inst.

6220 Culebra road

P.0. Drawer 28510

San Antonio, TX 78284

William C. Mc Gaughey

Southwest Research Institute

P.0. Drawer 28510

San Antonio, TX 78284

Wayne W. Rogers

Standard Precision Inc.

12311 S. Shoemaker Avenue

Sante Fe Springs, CA 90670

James D. Bean

Superior Tube Co.

Box 191

Norristown, PA 19404

Cohen Yoseph Bar

Systems Research Labs Inc.

2800 Indian Ripple Road

Dayton, $\mathrm{OH} 45440$

Parviz Mahmoodi

3M Company

Central Res. 201-BE

P.0. Box 33221

St. Pau1, MN 55133

Floyd A. Brown

Titanium Metals Corp.

100 Titanium Way

Toronto, $\mathrm{OH} 43964$

Edwin B. Henry, Jr.

U.S. Steel Research Laboratory

125 Jamison Lane

Monroeville, PA 15146

Bernard Strauss

USA Watertown

Army Mats. \& Mech. Res. Ctr.

Arsenal St

Watertown, MA 02160 
No. of

Copies

Patrick C. McEleney

USA Watertown Materials \& Mechanics Research Center

Arsenal Street

Watertown, MA 02172

Charles Federman

USG Commerce

National Bureau of Stds.

Bldg. 233 - Room A147

Washington, DC 20234

Donald G. Eitzen

USG Commerce

National Bureau of Stds.

Sound A147

Washington, DC 20234

Daniel J. Chwirut

USG HHS - Silver Spring

FDA-Bureau of Medical Devices

8757 Georgia Ave.

Silver Spring, MD 20910

Stewart D. Ebneter

USG Nuclear Regulatory

Commission

1075 Brentwood Or.

Pottstown, PA 19464

John Mittleman

USN Naval Coastal Systems Lab.

Panama City, FL 32407

Stephen D. Hart

USN Naval Research Lab.

4555 Overlook Ave. SW Code 8435

Washington, DC 20375

Edward L. Criscuolo

USN Naval Weapons Center

White Oak Lab-Code R34

Silver Spring, MD 20910
No. of

Copies

Kenneth Von Cook

Union Carbide Corp.

Oak Ridge National Lab

P.0. Box X B 1dg. 4500 S

Oak Ridge, TN 37830

Robert W. Mc Clung

Union Carbide Corp.

Oak Ridge Nat1. Lab.

P.0. Box $X$

Oak Ridge, TN 37830

Douglas L. Marriott

University of Illinois

1206 W. Green

Urbana, IL 61801

Steven Serabian

University of Lowell

Mechanical Engineering Dept.

North Campus

Lowe 11, MS 01854

Kermit A. Skeie

Uresco

10603 Midway Ave.

Cerritos, CA 90701

Edmund G. Henneke

VA Polytechnic Inst. \& State U. Dept. of Engineering Science and Mechanics

Blacksburg, VA 24061

John D. Fenton

Vought Corporation

P.0. Box 225907 MZ 6-16

Dal1as, TX 75265

A. L. Smith

Washington Public Power

Supply System

P.0. Box 968

Mail Drop 675

Richland, WA 99352 
No. of

Copies

Chuck Taylor

Western Zirconium

P. 0. Box 3208

Odgen, UT 84409

Eugene T. Hughes

Westinghouse Electric

Water Reactors Div.

Mat'1s \& NDE Analysis Box 355

Pittsburgh, PA 15230

E. T. Hughes

Westinghouse Electric Co.

P. 0. Box 355

Pittsburgh, PA 15230

D. C. Adamonis

Westinghouse Electric Corp.

Nuclear Technology Division

P.0. Box 355

Pittsburgh, PA 15230

Dominick J. De Paul

Westinghouse Electric Corp. Box 425

Monroeville, PA 15146

Calvin W. Mc Kee

Westinghouse Electric Corp.

P.D. Box 9175

Mail Code $\mathrm{N} 107$

Lester, PA 19113

David R. McLemore

Westinghouse Hanford Co.

WA-22

Box 1970

Richland, WA 99352

Mike C. Ts ao

Westinghouse R\&D

1310 Beulah Road

Pittsburgh, PA 15235
No. of

Copies

Robert $\boldsymbol{~}$. Loveless

Worthington Group

McGraw-Edison Co.

401 Worthington Avenue

Harrison, NJ 07029

Robert A. Eddy

Wyman-Gordon Co.

Worcester St

North Grafton, MA 01536

J. J. Lance

Yankee Atomic Electric Co.

1671 Worcester Road

Framingham, MA 01701

J. C. Spanner

Spanner Engineering Inc.

c/o Bestco

2939 Park Drive

P.0. Box 1370

Richland, WA 99352

FOREIGN

Lars-Ake Kornvik

A B Statens Anloggningsprovning

Kemistvagen 21, Box 51

S-183 21 TABY

SWEDEN

Don Birchon

Admiralty Materials Laboratory

Holton Health Poole

Dorser, ENGLAND

020-122-2711 
No. of

Copies

John Geoffrey Harris

Alcan Plate LTD

P. 0 . Box 383

Kitts Green RD B33 9QR

Birmingham

ENGLAND

David C. Broom

Aluminum $\mathrm{Co}$. of $\mathrm{C}$ anada Ltd.

Research Center

P.0. Box 8400 - Kingston

ontario K7L 4Z4 CANADA

Mervyn Brown

Aspex Services

214 Main Street East

Milton Ontario L9T 1N8

CANADA

ACE Sinclair

Berkeley Nuclear Laboratories

Research Division

Berkeley

Gloucestershire, CL $139 \mathrm{~PB}$

U.K.

E. E. Bor 700

Commission of the European Communities

Joint Research Center

21020 ISPRA (VA)

ITALY

J. A. De Raad

Delftweg 144

3046 NC Rotterdam

NETHERLANDS

0 . For $1 \mathrm{i}$

Det Norske Veritas

Veritasveien, 1

P. 0. Box 300

$\mathrm{N}-1322$ Hovik

NORWAY
No. of

Copies

Herbert Schaim

I M D T (Industrial \&

Scient if ic Equipment)

9 Keren $\mathrm{Ha}^{\prime}$ Yesod St P O B 1155

Beer-Sheva ISRAEL

P. Holler

Institut fur Zerstrarangs Frere

Prufverf ahren

Univ. Geb. 37

D-6600 Saarbrucken

WEST GERMANY

M. J. Whittle

NDT Application Centre

C.E.G.B. Scientific Services

Timpson Road

Manchester M23 9LL

U.K.

0. A. Kupc is

Ont ario Hydro

Tortonto, Ontario M8Z 5S4

CANADA

I. P. Bell

Risley Nuclear Labs

UKAEA

Risley Warrington

Cheshive

U.K.

$X$. Ede Iman

Sulzer Brothers Ltd.

Dept. 1513, NDT

$\mathrm{CH}-8401$ Winterthur

SWITZERLAND

P. Caussin

vincotte

1640 Rhode-Saint-Genese

BELGIUM

Horacio Prevedel

2577 Salgvero Street

Buenos Aires 1425

ARGENTINA 
No. of

Copies

\section{ONSITE}

50 Pacific Northwest Laboratory
A. S. Birks
S. H. Bush
L. J. Busse
R. A. Clark
S. R. Doctor (32)
G. B. Dudder
P. G. Heasler
P. H. Hutton
G. J. Posakony
G. P. Selby
F. A. Simonen
A. M. Sutey
T. T. Taylor
Technical Information (5)
Publishing Coordination 


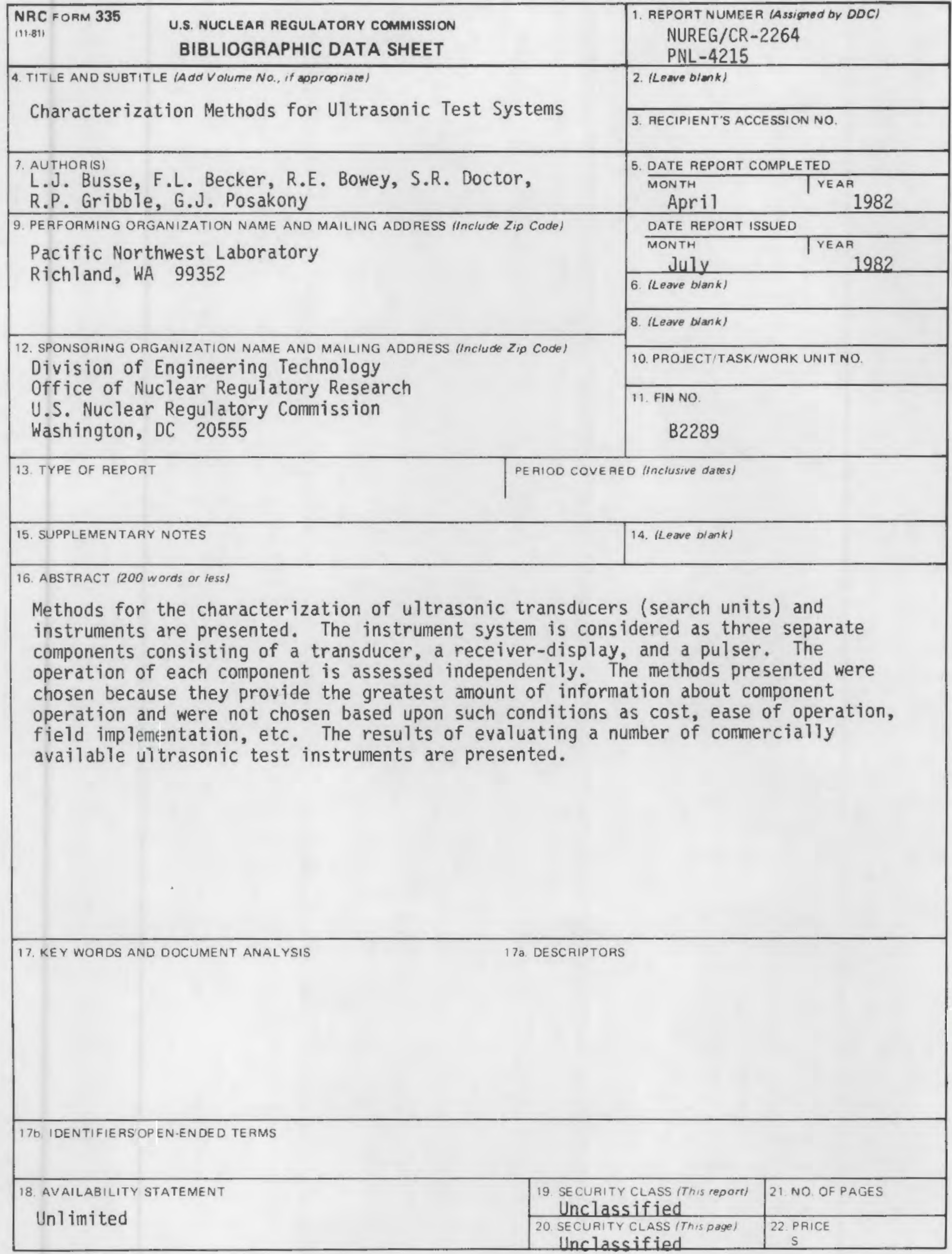


